\title{
Multi-Objective Optimization Models for Sustainable Perishable Intermodal Multi-Product Networks with Delivery Time Window
}

\author{
Chia-Nan Wang ${ }^{1}\left(\mathbb{D}\right.$, Nhat-Luong Nhieu ${ }^{1, * \mathbb{D}}$, Yu-Chi Chung ${ }^{1, *}$ and Huynh-Tram Pham ${ }^{2} \mathbb{D}$ \\ 1 Department of Industrial Engineering and Management, National Kaohsiung University of Science and \\ Technology, Kaohsiung 80778, Taiwan; cn.wang@nkust.edu.tw \\ 2 School of Industrial Engineering and Management, International University-Vietnam National University \\ HCMC, Ho Chi Minh 71300, Vietnam; phtram@hcmiu.edu.vn \\ * Correspondence: nnluong.iem@gmail.com (N.-L.N.); ycchung@nkust.edu.tw (Y.-C.C.)
}

\section{check for} updates

Citation: Wang, C.-N.; Nhieu, N.-L.; Chung, Y.-C.; Pham, H.-T.

Multi-Objective Optimization Models for Sustainable Perishable Intermodal Multi-Product Networks with Delivery Time Window. Mathematics 2021, 9, 379. https://doi.org/ $10.3390 /$ math 9040379

Academic Editors:

Nikolaos Sariannidis, Eleni Zafeiriou and Sofia Anastasiadou

Received: 13 January 2021

Accepted: 8 February 2021

Published: 14 February 2021

Publisher's Note: MDPI stays neutral with regard to jurisdictional claims in published maps and institutional affiliations.

Copyright: (c) 2021 by the authors. Licensee MDPI, Basel, Switzerland. This article is an open access article distributed under the terms and conditions of the Creative Commons Attribution (CC BY) license (https:/ / creativecommons.org/licenses/by/ $4.0 /)$.

\begin{abstract}
Supply chain network design problem is increasingly showing its importance, especially the perishable supply chain. This research develops a multi-objective mathematical model to design four-echelon intermodal multi-product perishable supply chain configuration in order to ensure a balance of the three pillars of sustainable development: economy, environment, and society. The optimization objective functions of the model are, respectively, minimizing costs, delivery time, emissions, and the supply-demand mismatch in time. The model addresses particular problems in the supply chain of fresh fruits, which is more challenging compared to other types of perishable products due to its seasonal characteristics. The study proposes a new approach that combines and standardizes the above objective functions into a single weighted objective function. The solution from the model supports the decision-making process at both strategic and tactical levels. Strategically, the model supports decisions about the location, size of facilities, product flows, and workforce level. Tactically, the decision variables provide information on harvest time, delivery time, the delivery route, and mode of transport. To demonstrate its practical applicability, the model is applied to Mekong Delta region, Vietnam, where a variety of fruit types, large yields, and high distribution demand in this region make designing a shared supply chain desirable for its overall economic, environmental, and social concerns. Moreover, sensitivity analysis regarding weights of different objectives is performed to assess possible changes in supply chain configurations. Application of this model to other perishable products, the addition of modes of transport, social policy, and uncertainty parameters may be suggested for future research.
\end{abstract}

Keywords: perishable supply chain network design; fresh fruit supply chain; intermodal transportation; sustainable pillars; multiple objective; delivery time window; mixed integer programming

\section{Introduction}

In the last two decades, consumers are more aware of the negative impact of their current eating habits and lifestyle. Therefore, the demand for consumption and the development of the health food supply industry has also shifted towards increasing [1]. Studies have shown that fruit consumption is growing because of the nutritional transition in many countries [2]. Fresh fruits are especially more preferable to consumers because they retain more nutrition than processed products such as antioxidants. The antioxidant content of the fruit is influenced by agricultural techniques, harvesting, and post-harvest preservation. The types of impacts during these processes such as heating, UV sterilization, and physical impact also affect the antioxidant content. Therefore, the fresh tissues of the fruit are an important storage site for their bioactive compounds [3]. Accordingly, activities of collecting, transporting, and distributing fresh fruit are becoming an important economic sector of many countries whose economy is heavily dependent on agriculture, such as Vietnam [4]. 
In the study by Amorim et al., a framework for the classification of perishability was proposed. This defines that a product that is considered perishable has at least one of the following three conditions: (1) the physical characteristics of the product change for the worse as decayed or depleted over time; (2) the probability that they are purchased by the customer decreases over time because of a decrease in value; (3) functionality of the product can reduce future risks in the opinion of some authorities [5]. Accordingly, fresh fruit has all three of the above conditions, so it can be considered a perishable product. In other words, the longer fruits take from harvest to shelves, the lower their quantity and quality [6]. The decline took place throughout activities in the supply chain, but mainly in transportation and distribution [7]. Therefore, in designing a perishable product supply chain, decisions about transit times are an important factor along with decisions about the location and size of facilities.

Designing a sustainable supply chain requires consideration of environmental, social, and economical influences from decision-makers. The environment is under increasing pressure as a result of population growth and the use of fossil fuels [8]. The impact of supply chain on the environment is controlled primarily through limiting emissions in logistics activities $[9,10]$. For fresh fruit supply chain, the emissions mainly come from transport with the associated refrigeration equipment while the emission from low-energy packaging and sorting activities is insignificant. On the social factor, decision-makers' employment strategy in supply chain design is essential to ensure sustainable development of local rural society. In terms of economic impact, harvest and supplying timing is critical to economic gain of both farmers and traders. Because fresh fruit is a seasonal agricultural product, its quantity and price are dependent on time. The situation in which a large quantity of fruit available on the market at low prices directly affects the economic efficiency of the entire supply chain with the biggest impact on the farmers. In the opposite situation, when the demand is high and the yield is low, it leads to many difficulties for traders. In order to limit the frequency of these situations, considerations of harvest time and time window during shipping are suggested in decisions about the design and operation of the fresh fruit supply chain.

Finally, designing a shared supply chain for a variety of fruits where production and logistics activities can be centrally managed is highly desirable for many localities [11]. In the case of Vietnam, for example, Mekong Delta region is considered the largest supplier of various fruits for the country. The variety of fruit types, large yields, and high distribution demand in this region make it imperative to design a shared supply chain for a variety of fruits. In particular, it is desirable for the production, harvest, collection, packaging, sorting, crossdocking, and distribution activities to be centrally managed to optimize costs while still meeting sustainability requirement and customer satisfaction. In addition, the substitution of a shared supply chain for individual ones assists managers to control the phase difference between the harvest season and the season with high market demand.

This study addresses all the issues mentioned above by a synthesis approach: (1) Developing a multiple objective mixed integer programming (MIP) model for the four-echelon multi-product intermodal sustainable fresh fruit supply chain network design problem. The model supports decisions about the location, size, workforce of facilities, product flows, routes, and modes of transport across the supply chain simultaneously. The objectives that this model aims to optimize include cost, delivery time, transportation emissions, and delivery on high demand time window. (2) Proposing a weighted balancing objective function to find reconciled solutions among the objective functions based on their importance. Along with that is a method to estimate the weights between the objective functions from the point of view of multiple decision makers. (3) Providing recommendations for the design and operation of a shared supply chain of fresh fruits in the case of the Mekong Delta in Vietnam. The solution of the model is calculated based on data and regional characteristics such as type of fruit, yield, cost, mode of transport, and transport infrastructure. (4) Analysis of variation in the design of the supply chain by adjusting the weight of the objective functions in different scenarios, thereby assisting decision-makers in predicting 
changes in supply chain configuration when priority of the objective functions changes in the future.

\section{Literature Review}

\subsection{Supply Chain Network Design}

The rapid development of the globalization of production and trade have created a great motivation for the study of supply chain management. Researches revolve around core questions of a supply chain such as product flow, mode of transport, and facility location. In addition, factors of environmental, social, risk, and collaborative impacts are also considered as guarantees for sustainable development $[12,13]$. The proposed methods to answer the above questions are becoming increasingly diverse, with optimization being the mainstream [14].

In the era of mass customization production, new product development requirements influence the design and operation of supply chains. A multi-objective optimization model is proposed to support decisions to minimize costs and maximize customer satisfaction [15]. For regions that have enacted legal system on the environment, the emissions are translated into a form of costs such as taxes and penalties. In this way, single-target optimization models that are related to cost can also reduce the environmental impact of the supply chain design problem [16]. However, cost is not the only factor affecting supply chain efficiency. By goal programming approach, the solution proposes the facility location of a supply chain which satisfy the criteria of cost, environmental impact, regional advantage, and investment company's preference, simultaneously [17]. The design of multi-product supply chain networks with multiple stakeholders makes this problem grouped with NPHard problems. Heuristic algorithms are then used to find feasible solutions to complex supply chain configurations [18]. Besides solving strategic issues, tactical and operational decisions also need more attention to increase supply chain competitiveness [14]. This competitiveness can be analyzed by price, customer satisfaction, product quality, supply capacity, and so on. Operational and tactical solutions such as transport planning, modes of transport in each area, and workforce scheduling under certain or uncertain conditions of parameters are considered the way to optimize the supply [19].

\subsection{Perishable Supply Chain Network Design}

Due to the requirements of special conditions in production and logistics services, the perishable supply chain network design problem (PSCNDP) is seen as a separate branch of research on supply chain design. Some studies ignore decisions about supply chain configurations such as the location of facilities and product flows. In inventory management where products have limited shelf-life, the study suggests a method to determine the optimal inventory level in the influence of external factors such as inflation or price fluctuations [20]. As discussed above, perishable supply chains have with them an inverse time-value correlation. This correlation has an impact on supply chain costs in terms of inventory and transport batch size. In order to analyze this issue, a model to support supply chain strategy development is proposed [21]. Another study analyzed inventory efficiency using a game-based empirical approach based on two factors: perishability and production limitation of the products [22]. Apart from cash flow and product flow, information flow also plays an important role in the supply chain. Control of product quality and origin information is essential to the supply chain of perishable products. An information sharing platform is recommended by authors after using Petri Net modeling to analyze information correlation of the supply chain [23].

For studies that include decisions about supply chain configuration, Rong et al. [24] in their research has developed a minimized cost MIP model for food distribution and production planning with emphasis on temperature control in logistics operations to ensure the highest product quality possible. In the study by Etemadnia et al. [25], another MIP model is proposed with the aim of minimizing costs in the context of considering a choice between two modes of transport: low-cost roadway and higher-cost airway. In addition, 
this model also offers the right options for the location of hubs to achieve economic efficiency in investment. In the article by de Kaize et al. [26]., the heterogeneity in quality deterioration of different products under different temperature conditions is controlled through a MIP model which includes decisions about hubs location, process, and inventory. Dutta and Shrivastava's work presents a non-linear model for a three-echelon supply chain with suppliers, processors, and consumers [27]. Under uncertain conditions, the study proposes a supply chain policy to optimize costs when the risk parameters are both low and high.

Besides economic efficiency, time-related factors are also considered by researchers as the objective function of the optimal models. Bushuev and Guiffrida have developed a mathematical model to position the optimal time window for deliveries in the supply chain through the analysis of the cumulative distribution functions of the time of delivery that determine the optimal position of the time window for delivery. The results of this study allow components at the top of the supply chain to make cost-effective decisions while minimizing the cost of penalties when goods are delivered early or late [28]. The MIP model introduced by Catalá et al. simultaneously optimizes cost and customer satisfaction across multiple periods. This level of satisfaction is estimated based on the difference between the quantity of goods supplied and the demand over time. The authors handle these two optimal objectives with the goal programming approach [29]. Perishable product supply chains become more complex when both the demand in the market and the supply of the product is seasonal. This is one of the characteristics of agricultural products such as fruits and vegetables. Razmi et al. has developed an integrated mathematical model that optimizes the product flow in the supply chain to maximize cash flow value under the constraints of seasonal product supply. This study also proposes the genetic algorithm (GA) as a tool for solving larger problems [30].

\subsection{Sustainable Perishable Supply Chain Network Design}

The perishable supply chain design studies discussed above focus on the economic performance of the supply chain. Currently, supply chains are under greater pressure for balanced development on all three pillars of sustainability. The rest of the research on sustainable perishable supply chain design problems (SPSCNDPs) is about environmental and social factors [31]. The review of article of Koberg and Longoni shows that the sustainable development of multi-tier supply chain requires the cooperation of all stakeholders. Not so, this issue also requires the contribution of third parties such as nonprofit organizations (NGOs). In other words, environmental and social issues in the supply chain need to be considered from design to operation [9].

An optimized model has been developed for perishable supply chains that simultaneously controls the costs, ability to respond to market demand, and the environmental impact of the supply chain introduced by Musavi and Bozorgi-Amiri [32]. Govindan et al. [7] introduced another MIP model for the two-echelon supply chain that addresses costs and environmental impacts minimized. Moreover, this model also ensures high utilization of the logistics system and delivery control with the time-window. Biuki et al. [33] has integrated a social factor in its research through the introduction of workforce constraints in the multiple objective optimization model. The environmental and cost objective functions are transformed into a single-target version through fuzzy formulation [34]. The authors also suggest metaheuristic algorithms to find solutions to large size problems.

In order to ensure both quality and quantity of products throughout the supply chain, the study of Bortolini et al. [35] viewed delivery time as the third target function that should be minimized in the model along with costs and emissions. Besides, a few other factors are also included in the models optimized for PSCNDPs, such as delivery rate [36] or energy cost with the effects of climate [37]. 


\subsection{Literature Review Summary}

In summary, past studies in PSCNDPs for the fresh fruit industry have individually pointed out the neccesity of optimization of location and size of facilities, product flows, modes of transport, and workforce in terms of time-window considerations of both supply and demand. The objectives that should be considered in optimization are the economic efficiency in terms of cost, the environmental impact in terms of emissions, the assurance of the quality of the product in terms of the delivery time, and the customer satisfaction level reflected in the seasonal product availability. Therefore, this study develops a multitarget optimized mathematical model for a shared fresh fruit supply chain network design problem, which integrates the above-mentioned decisions, factors, and objectives.

\section{Methodology}

In this study, a multiple objective mixed integer programming model is developed in order to find the integrated solution for the configuration of a four-echelon supply chain and its intermodal transportation plan. The supply chain includes fruit gardens, local collection hubs, crossdocking centers, and retail stores, as illustrated in Figure 1. The model's solution supports strategic decision making on the location, size, and workforce level of local hubs and crossdocking centers. A transport plan with information about the quantity, time, and mode of transport is also determined by this solution.

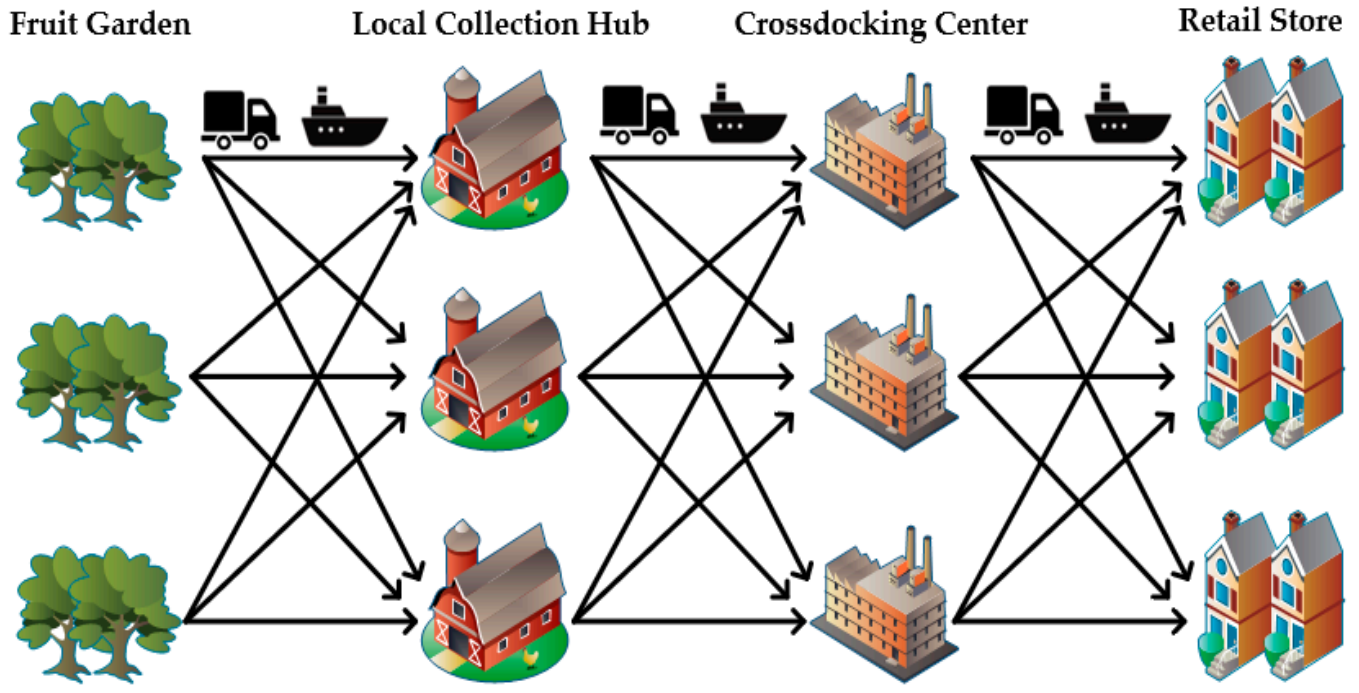

Figure 1. The four-echelon fruit supply chain.

\subsection{Sets and Indices}

This MIP model is developed with nine sets that define the parameters and decision variables which showed in Table 1:

1. The set of fruits are considered as the products of the supply chain.

2. The set of fruit gardens that supply products for the supply chain.

3. The set of potential local collection hubs.

4. The set of potential crossdocking centers.

5. The set of retail stores where fruits are consumed.

6. The set of investment scales of facilities as local collection hubs and crossdocking centers.

7. The set of transportation modes.

8. The set of model's objective functions.

9. The set of decision makers whose opinions affect objective functions' weight. 
Table 1. List of sets.

\begin{tabular}{ccc}
\hline Set Notation & Set Indices & Description \\
\hline $\mathrm{N}$ & $n$ & Types of fruit \\
$\mathrm{G}$ & $i$ & Fruit gardens \\
$\mathrm{H}$ & $j$ & Potential local hubs \\
$\mathrm{C}$ & $k$ & Potential Crossdocking centers \\
$\mathrm{S}$ & $\mathrm{s}$ & Fruit stores \\
$\mathrm{L}$ & $l$ & Facility scales \\
$\mathrm{M}$ & $\mathrm{m}$ & Transportation modes \\
$\mathrm{P}$ & $\mathrm{p}$ & Objective functions \\
$\mathrm{DM}$ & $\mathrm{d}$ & Decision makers \\
\hline
\end{tabular}

\subsection{Parameters and Decision Variables}

Parameters pertaining to the gardens, hubs, crossdocking centers, transportation, and customer demands are listed in Table 2. The first group of parameters in the table is fixed costs and variable costs related to hubs, crossdocking center, and transportation such as the initial investment cost for facilities according to the size of construction, unit transport cost of the transport modes, and unit annual labor costs at the facilities. The second group is facility specifications, comprising distances between the nodes, its capacity, labor, and production rate. Thirdly, vehicle-related parameters include vehicle capacity, design speed, and environmental impact factor. Finally, the mathematical model also considers the capacity to supply fruit in the gardens with a timeframe for harvest, which is defined by the interval $\left[H A_{i n}, H A_{i n}+\varepsilon_{n}\right]$. Likewise, the other parameters are the fruit demand for the stores and the time window for delivery, which is determined by the interval $\left[T W_{s n}^{\text {start }}, T W_{s n}^{\text {end }}\right]$.

Table 2. Model parameters.

\begin{tabular}{|c|c|c|c|}
\hline Group & Notation & Parameters & Unit \\
\hline \multirow{5}{*}{1} & $F C_{l}^{h u b}$ & Investment cost for local hub with facility scale $l$ & USD \\
\hline & $F C_{l}^{c e n t e r}$ & $\begin{array}{l}\text { Investment cost for crossdocking center with } \\
\text { facility scale } l\end{array}$ & USD \\
\hline & & Unit shipping cost with transportation mode $m$ & USD/ton-km \\
\hline & $L C^{h u b}$ & Annual labor cost for local hubs & USD/person \\
\hline & LCenter & Annual labor cost for crossdocking centers & USD/person \\
\hline \multirow{13}{*}{2} & $D I_{i j m}^{h u b}$ & $\begin{array}{c}\text { Distance from fruit garden } i \text { to local hub } j \text { with } \\
\text { transportation mode } m\end{array}$ & $\mathrm{Km}$ \\
\hline & $D I_{j k m}^{c e n t e r}$ & $\begin{array}{l}\text { Distance from local hub } j \text { to crossdocking center } \\
k \text { with transportation mode } m\end{array}$ & $\mathrm{Km}$ \\
\hline & $D I_{k s m}^{s t o r e}$ & $\begin{array}{l}\text { Distance from crossdocking center } k \text { to store } s \\
\text { with transportation mode } m\end{array}$ & $\mathrm{Km}$ \\
\hline & $C A P_{l}^{h u b}$ & Local hub designed capacity with facility scale $l$ & Ton/year \\
\hline & $C A P_{l}^{\text {center }}$ & $\begin{array}{l}\text { Crossdocking center designed capacity with } \\
\text { facility scale } l\end{array}$ & Ton/year \\
\hline & $P T^{h u b}$ & Designed crossdocking time for local hub & Hour/ton \\
\hline & $P T^{\text {center }}$ & $\begin{array}{c}\text { Designed crossdocking time for crossdocking } \\
\text { center }\end{array}$ & Hour/ton \\
\hline & $\theta^{h u b}$ & Minimum capacity utilization for local hub & $\%$ \\
\hline & $\theta^{\text {center }}$ & $\begin{array}{l}\text { Minimum capacity utilization for crossdocking } \\
\text { center }\end{array}$ & $\%$ \\
\hline & $\varphi^{h u b}$ & Maximum labor working hour for local hub & Hour \\
\hline & $\varphi^{\text {center }}$ & $\begin{array}{c}\text { Maximum labor working hour for crossdocking } \\
\text { center }\end{array}$ & Hour \\
\hline & $\omega^{h u b}$ & Workforce production rate for local hub & Ton/hour \\
\hline & $\omega^{\text {center }}$ & $\begin{array}{l}\text { Workforce production rate for crossdocking } \\
\text { center }\end{array}$ & Ton/hour \\
\hline
\end{tabular}


Table 2. Cont.

\begin{tabular}{|c|c|c|c|}
\hline Group & Notation & Parameters & Unit \\
\hline \multirow{3}{*}{3} & $P L_{m}$ & Vehicle payload with transportation mode $m$ & Ton \\
\hline & $V_{m}$ & $\begin{array}{l}\text { Vehicle designed velocity with transportation } \\
\text { mode } m\end{array}$ & $\mathrm{Km} /$ hour \\
\hline & $E_{m}$ & $\begin{array}{l}\mathrm{CO} 2 \text { emission coefficient with transportation } \\
\text { mode } m\end{array}$ & $\mathrm{Kg} /$ ton-km \\
\hline \multirow{6}{*}{4} & $S U P_{\text {in }}$ & $\begin{array}{l}\text { Annual supply capacity of fruit } n \text { in fruit } \\
\text { garden } i\end{array}$ & Ton \\
\hline & $D E_{S n}$ & Annual demand of fruit $n$ in store $s$ & Ton \\
\hline & $H A_{\text {in }}$ & $\begin{array}{l}\text { Available harvest date of fruit } n \text { in fruit garden } i \\
\text { (Value 0 0:00 January 1st) }\end{array}$ & Hour \\
\hline & $\varepsilon_{n}$ & Maximum waiting time for harvest of fruit $n$ & Hour \\
\hline & $T W_{s n}^{\text {start }}$ & $\begin{array}{l}\text { Start date of time window for fruit } n \text { in store } s \\
\text { (Value 0 0:00 January 1st) }\end{array}$ & Hour \\
\hline & $T W_{s n}^{e n d}$ & $\begin{array}{l}\text { End date of time window for fruit } n \text { in store } s \\
\text { (Value 0 0:00 January 1st) }\end{array}$ & Hour \\
\hline
\end{tabular}

Decision variables for making supply chain configuration decisions are described in Figure 2 and summarized in Table 3 . The decision variables $y_{j l}^{h u b}, z_{j}^{\text {hub }}$ describe construction location, size, and workforce level of local hub, respectively. Similarly, decision variables for crossdocking centers are $y_{j l}^{\text {center }}$ and $z_{k}^{\text {center }}$. Regarding transportation plan, the decision variables $v_{i j m n}^{h u b}, x_{i j m n}^{h u b}$ propose routes, quantities, and modes of transport from the fruit gardens to local collection hubs. Meanwhile, the decision variables $v_{j k m n}^{\text {center }}, x_{j k m n}^{\text {center }}, v_{k s m n}^{\text {store }}, x_{k s m n}^{\text {store }}$ are used with the same rules for transporting from local collection hubs to crossdocking centers and from crossdocking centers to retail stores.

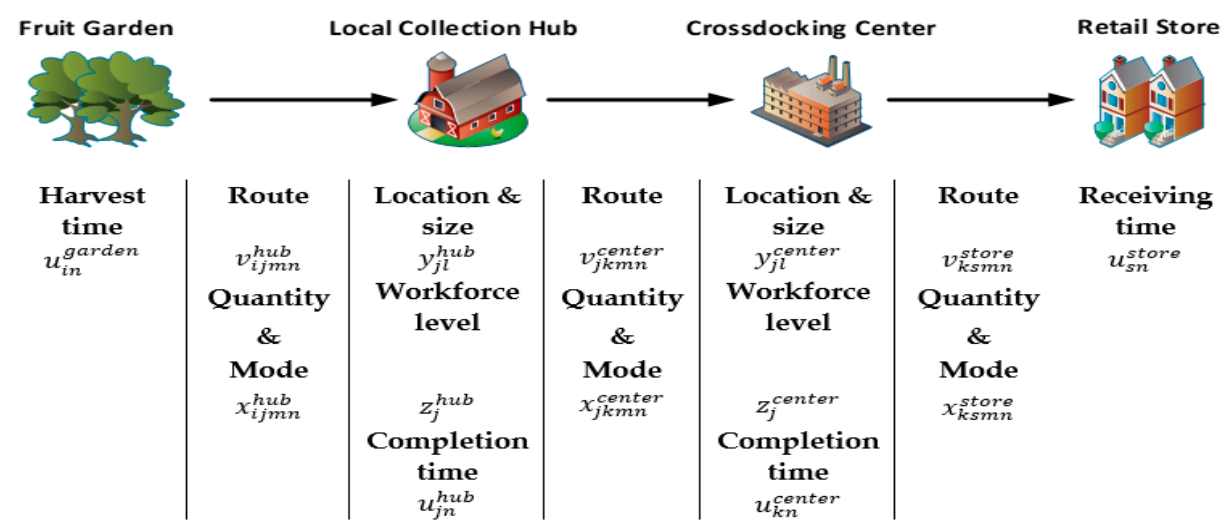

Figure 2. Supply chain configuration variables.

On the other hand, variables $u_{i n}^{\text {garden }}, u_{j n}^{\text {hub }}, u_{k n}^{\text {center }}, u_{s n}^{\text {store }}$ specify the latest completion time for harvesting, crossdocking, and transportation at fruit gardens, local hubs, crossdocking centers, and stores. Finally, based on the difference between the value of $u_{s n}^{\text {store }}$ and the delivery time window, the model determines the delay or early of deliveries with two variables $t_{s n}^{\text {delay }}, t_{s n}^{\text {earlier. }}$. 
Table 3. Model decision variables.

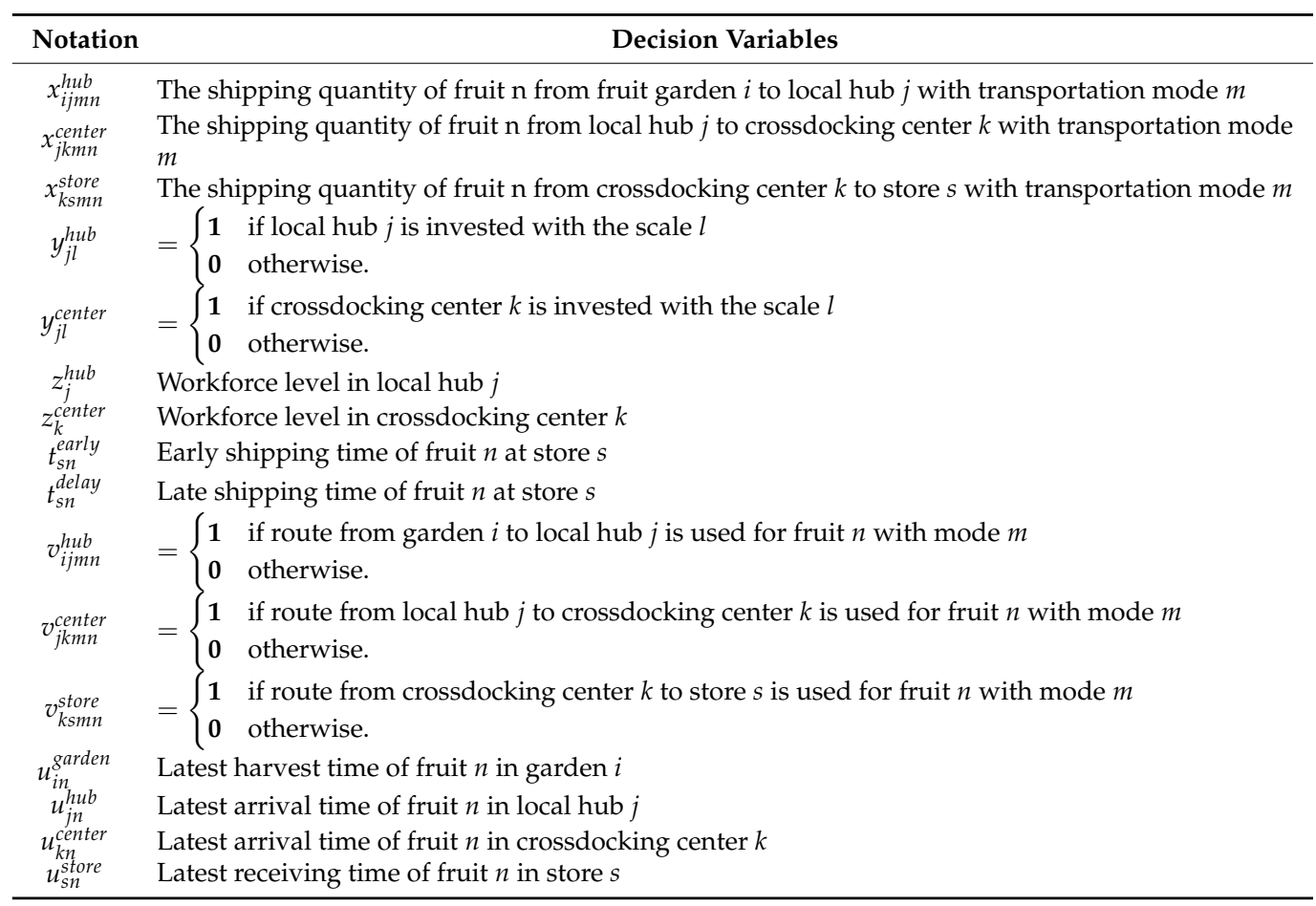

\subsection{Objective Functions}

\subsubsection{Single Objective Functions}

The first model's objective function is minimizing the total cost (USD) of the supply chain. In Equation (1), the first term describes total initial investment cost to establish local hubs and crossdocking centers. The second term determines total transportation cost from the fruit gardens to retail stores in the end of the supply chain.

$$
\begin{aligned}
\text { Minimize } f^{1}= & \left(\sum_{j=1}^{H} \sum_{l=1}^{L} y_{j l}^{h u b} \times F C_{l}^{h u b}+\sum_{k=1}^{C} \sum_{l=1}^{L} y_{j l}^{\text {center }} \times F C_{l}^{\text {center }}\right) \\
& +\left(\sum_{i=1}^{G} \sum_{j=1}^{H} \sum_{m=1}^{M} \sum_{n=1}^{N} x_{i j m n}^{h u b} \times T C_{m} \times D I_{i j m}^{h u b}\right. \\
& +\sum_{j=1}^{H} \sum_{k=1}^{C} \sum_{m=1}^{M} \sum_{n=1}^{N} x_{j k m n}^{\text {center }} \times T C_{m} \times D I_{j k m}^{\text {center }} \\
& \left.+\sum_{k=1}^{C} \sum_{s=1}^{S} \sum_{m=1}^{M} \sum_{n=1}^{N} x_{k s m n}^{\text {store }} \times T C_{m} \times D I_{k s m}^{\text {store }}\right) \\
& +\left(\sum_{j=1}^{H} z_{j}^{h u b} \times L C^{h u b}+\sum_{k=1}^{C} z_{k}^{\text {center }} \times L C^{\text {center }}\right)
\end{aligned}
$$

Because of the rapid decline in the quality of the fruit after the harvest, products need to be transported as quickly as possible to the consumer in order to minimize losses. Thus, minimizing total delivery time (hour) is the second objective function of the MIP which is described in Equation (2). The decisions about the route and the mode of transport can directly affect transit times.

$$
\begin{aligned}
\text { Minimize } f^{2}= & \sum_{i=1}^{G} \sum_{j=1}^{H} \sum_{m=1}^{M} \sum_{n=1}^{N} \frac{x_{i j m n}^{h u b}}{P L_{m}} \times \frac{D I_{i j m}^{h u b}}{V_{m}}+\sum_{j=1}^{H} \sum_{k=1}^{C} \sum_{m=1}^{M} \sum_{n=1}^{N} \frac{x_{j k n n}^{\text {center }}}{P L_{m}} \times \frac{D I_{j k m}^{\text {center }}}{V_{m}} \\
& +\sum_{k=1}^{C} \sum_{s=1}^{S} \sum_{m=1}^{M} \sum_{n=1}^{N} \frac{x_{k s m n}^{\text {store }}}{P L_{m}} \times \frac{D I_{k s m}^{\text {store }}}{V_{m}}
\end{aligned}
$$


The timing of harvest for fruits is seasonal and so is their demand in the consumer markets. The ability to bring product to market during a period of high demand creates more profit for the entire supply chain while minimizing postharvest losses due to fruit reaching the end of their shelf life. Therefore, the model aims to minimize the time that goods arrive sooner or later than its time window at stores, which is called on-time delivery factor (hour) in this article and showed in Equation (3).

$$
\text { Minimize } f^{3}=\sum_{s=1}^{S} \sum_{n=1}^{N}\left(t_{s n}^{\text {early }}+t_{s n}^{\text {delay }}\right)
$$

Last but not least, the sustainable supply chain ensures that its impacts on the environment are minimal. Since this study focuses on the supply chain for freshly consumed fruit without going through industrial processing in facilities, emissions are mainly generated during transportation. Thus, the next objective function that calculated in Equation (4) is to minimize transportation emissions ( $\mathrm{Kg} \mathrm{CO} 2)$.

$$
\begin{aligned}
\text { Minimize } f^{4}= & \sum_{i=1}^{G} \sum_{j=1}^{H} \sum_{m=1}^{M} \sum_{n=1}^{N} x_{i j m n}^{h u b} \times D I_{i j m}^{h u b} \times E_{m} \\
& +\sum_{j=1}^{H} \sum_{k=1}^{C} \sum_{m=1}^{M} \sum_{n=1}^{N} x_{j k m n}^{\text {center }} \times D I_{j k m}^{\text {center }} \times E_{m} \\
& +\sum_{k=1}^{C} \sum_{s=1}^{S} \sum_{m=1}^{M} \sum_{n=1}^{N} x_{k s m n}^{\text {store }} \times D I_{k s m}^{\text {store }} \times E_{m}
\end{aligned}
$$

\subsubsection{Weighted Balancing Objective Function}

The supply chain with optimal transportation time configurations can lead to an increase in overall costs and vice versa. Similarly, cost-minimizing efforts can increase the likelihood of the fruit being delivered to the store during times of low demand with higher emissions. In order to find solutions that compromise the objective functions at the same time, this article uses a weighted balancing objective function, which is described in Equation (5).

$$
\text { Minimize } f=\sum_{p=1}^{P} W^{p} \times\left(\frac{f^{p}-f^{p *}}{f^{p *}}\right)
$$

where $f^{p *}$ is the optimal value of objective function $p$ and $W^{p}$ is the weight of objective function $p$ which is determined by two steps. Firstly, we develop a pairwise comparison matrix $Q$ between the objective functions through the survey of experts or decision makers with the linguistic term scale in Table 4.

Table 4. Linguistic term scale

\begin{tabular}{cc}
\hline Definition of Linguistic Term Scale & Numerical \\
\hline Equally important & 1 \\
Weakly important & 3 \\
Essentially important & 5 \\
Very strongly important & 7 \\
Absolutely important & 9 \\
Intermediate value between two adjacent judgments & $2,4,5,6$ \\
\hline
\end{tabular}

$$
Q=\left[\begin{array}{cccc}
1 & a_{12} & \ldots & a_{1 P} \\
1 / a_{12} & 1 & \ldots & a_{2 P} \\
\ldots & \ldots & 1 & \ldots \\
1 / a_{1 P} & 1 / a_{2 P} & \ldots & 1
\end{array}\right]
$$


Secondly, we calculate the weight of objective function $p$ according to the expert $d$ by the average of normalized columns (ANC) as Equation (6) after consistency verification.

$$
w_{p d}=\frac{1}{P} \sum_{h=1}^{P} \frac{a_{g h}}{\sum_{g=1}^{P} a_{g h}} \quad p \in P ; d \in D M
$$

Finally, the value of the weight is its average value from the different decision makers, which is presented Equation (7).

$$
W^{p}=\frac{\sum_{d=1}^{D M} w_{p d}}{D M} \quad p \in P
$$

\subsection{Model Constraints}

The constraints are presented in Constraints (8) to (11) to ensure that the quantity of fruit delivered in the supply chain meets demand at the store. Besides that, the delivered quantity does not exceed the supply capacity of the garden. At local hubs and crossdocking centers, the total amount of fruit to be transported should not exceed the amount received.

$$
\begin{array}{ll}
S U P_{\text {in }} \geq \sum_{j=1}^{H} \sum_{m=1}^{M} x_{i j m n}^{h u b} & i \in G, n \in N \\
\sum_{i=1}^{G} \sum_{m=1}^{M} x_{i j m n}^{h u b} \geq \sum_{k=1}^{C} \sum_{m=1}^{M} x_{j k m n}^{\text {center }} & j \in H, n \in N \\
\sum_{j=1}^{H} \sum_{m=1}^{M} x_{j k m n}^{\text {center }} \geq \sum_{s=1}^{S} \sum_{m=1}^{M} x_{k s m n}^{\text {store }} & k \in C, n \in N \\
\sum_{k=1}^{C} \sum_{m=1}^{M} x_{k s m n}^{\text {store }} \geq D E_{s n} & s \in S, n \in N
\end{array}
$$

Moreover, the amount of cargo transported on each route with a mode of transport, if any, cannot be less than the vehicle's payload according to Constraints (12) to (14).

$$
\begin{aligned}
& \left\{\begin{array}{c}
x_{i j m n}^{h u b} \leq B i g M \times v_{i j m n}^{h u b} \\
x_{i j m n}^{h u b} \geq P L_{m}-B i g M \times\left(1-v_{i j m n}^{h u b}\right)
\end{array} \quad i \in G, j \in H, m \in M, n \in N\right. \\
& \left\{\begin{array}{c}
x_{j k m n}^{\text {center }} \leq B i g M \times v_{j k m n}^{\text {center }} \\
x_{j k m n}^{\text {center }} \geq P L_{m}-B i g M \times\left(1-v_{j k m n}^{c e n t e r}\right)
\end{array} \quad j \in H, k \in C, m \in M, n \in N\right. \\
& \left\{\begin{array}{c}
x_{k s m n}^{\text {store }} \leq \text { Big } M \times v_{k s m n}^{\text {store }} \\
x_{k s m n}^{\text {store }} \geq P L_{m}-B i g M \times\left(1-v_{k s m n}^{\text {store }}\right)
\end{array} \quad k \in C, s \in S, m \in M, n \in N\right.
\end{aligned}
$$

In Constraint (15), the harvest timing should be in the harvest time window $\left[H A_{\text {in }}, H A_{\text {in }}+\varepsilon_{n}\right]$ of certain fruit at certain gardens. Then, the latest completion time which includes transportation time and crossdocking time for a certain fruit at local hubs and crossdocking centers is determined according to Constraints (15) to (17). Based on the completion time at the stores, the total time the fruit is delivered earlier or later than the high demand time window $\left[T W_{s n}^{\text {start }}, T W_{s n}^{\text {end }}\right]$ calculated by Constraints (19) and (20).

$$
\begin{aligned}
& \left\{\begin{array}{c}
u_{\text {in }}^{\text {garden }} \geq H A_{\text {in }} \\
u_{i n}^{\text {garden }} \leq H A_{\text {in }}+\varepsilon_{n}
\end{array} \quad i \in G, n \in N\right. \\
& u_{i n}^{\text {garden }}+\left(\frac{D I_{i j m}^{h u b}}{V_{m}} \times v_{i j m n}^{h u b}\right) \leq u_{j n}^{h u b} \quad i \in G, j \in H, m \in M, n \in N
\end{aligned}
$$




$$
\begin{gathered}
u_{j n}^{\text {hub }}+\left(\frac{D I_{i j m}^{\text {hub }}}{V_{m}} \times v_{j k m n}^{\text {center }}\right)+\left(P T^{h u b} \times v_{j k m n}^{\text {center }}\right) \leq u_{k n}^{\text {center }} \\
j \in H, k \in C, m \in M, n \in N \\
u_{k n}^{\text {center }}+\left(\frac{D I_{k s m}^{\text {store }}}{V_{m}} \times v_{k s m n}^{\text {store }}\right)+\left(P T^{\text {center }} \times v_{k s m n}^{\text {store }}\right) \leq u_{s n}^{\text {store }} \\
k \in C, s \in S, m \in M, n \in N \\
t_{s n}^{\text {early }} \geq T W_{s n}^{\text {start }}-u_{s n}^{\text {store }} \quad s \in S, n \in N \\
t_{s n}^{\text {delay }} \geq u_{s n}^{\text {store }}-T W_{s n}^{\text {end }} \quad s \in S, n \in N
\end{gathered}
$$

The Constraints (21) and (23) ensure that the total amount of fruit to be transported does not exceed the design capacity of local hubs and crossdocking centers. These constraints also ensure that the utilization rate of the facilities is not too low for the efficiency of the investment. At each potential location, only one investment scale can be selected for facilities according to Constraints (22) and (24).

$$
\begin{aligned}
& \left\{\begin{array}{c}
\sum_{k=1}^{C} \sum_{m=1}^{M} \sum_{n=1}^{N} x_{j k m n}^{\text {center }} \leq \sum_{l=1}^{L} y_{j l}^{h u b} \times C A P_{l}^{h u b} \\
\sum_{k=1}^{C} \sum_{m=1}^{M} \sum_{n=1}^{N} x_{j k m n}^{\text {center }} \geq \sum_{l=1}^{L} y_{j l}^{h u b} \times C A P_{l}^{h u b} \times \theta^{h u b}
\end{array} \quad j \in H\right. \\
& \sum_{l=1}^{L} y_{j l}^{h u b}=1 \quad j \in H \\
& \left\{\begin{array}{c}
\sum_{s=1}^{S} \sum_{m=1}^{M} \sum_{n=1}^{N} x_{k s m n}^{\text {store }} \leq \sum_{l=1}^{L} y_{k l}^{\text {center }} \times C A P_{l}^{\text {center }} \\
\sum_{s=1}^{S} \sum_{m=1}^{M} \sum_{n=1}^{N} x_{k s m n}^{\text {store }} \geq \sum_{l=1}^{L} y_{k l}^{\text {center }} \times C A P_{l}^{\text {center }} \times \theta^{\text {center }}
\end{array} \quad k \in C\right. \\
& \sum_{l=1}^{L} y_{k l}^{\text {center }}=1 \quad k \in C
\end{aligned}
$$

In constraints (25) and (26), the total amount of fruit transported should not exceed the workforce capacity at facilities.

$$
\begin{array}{ll}
\sum_{k=1}^{C} \sum_{m=1}^{M} \sum_{n=1}^{N} x_{j k m n}^{\text {center }} \leq z_{j}^{h u b} \times \varphi^{h u b} \times \omega^{h u b} & j \in H \\
\sum_{k=1}^{C} \sum_{m=1}^{M} \sum_{n=1}^{N} x_{k s m n}^{\text {store }} \leq z_{k}^{\text {center }} \times \varphi^{\text {center }} \times \omega^{\text {center }} & k \in C
\end{array}
$$

Constraints (27) ensures that the number of employee and the shipped quantity are integer variables. Meanwhile, all of the decision variables in this MIP model are non-negative.

$x_{i j m n}^{h u b}, x_{j k m n}^{\text {center }}, x_{k s m n}^{\text {store }}, z_{j}^{h u b}, z_{k}^{\text {center }}$ are integer $\quad i \in G, j \in H, k \in C, s \in S, m \in M, n \in N$

\section{Results}

\subsection{Case Study}

This study focuses on the case study of domestic fresh fruit supply chain in Mekong Delta, Vietnam. This region includes thirteen provinces that have advantages in agricultural production, and is one of the largest food supply regions in Vietnam. In the Official Letter No. 1648 issued by the Ministry of Agriculture of Vietnam on the development of fruit production in the period of 2013-2020, this region is planned to develop and produce eleven major types of fruits, with the total planting area described in the Table 5 and Figure 3 [38]. 
Table 5. Major fruit in Mekong Delta, Vietnam

\begin{tabular}{ccc}
\hline No. & Major Fruit & Area (Hectares) \\
\hline 1 & Dragon fruit & 7300 \\
2 & Mango & 31,600 \\
3 & Rambutan & 5500 \\
4 & Durian & 10,500 \\
5 & Star apple & 5000 \\
6 & Pomelo & 25,000 \\
7 & Longan & 26,300 \\
8 & Banana & 21,400 \\
9 & Pineapple & 21,000 \\
10 & Orange & 26,250 \\
11 & Mandarin & 5250 \\
\hline
\end{tabular}

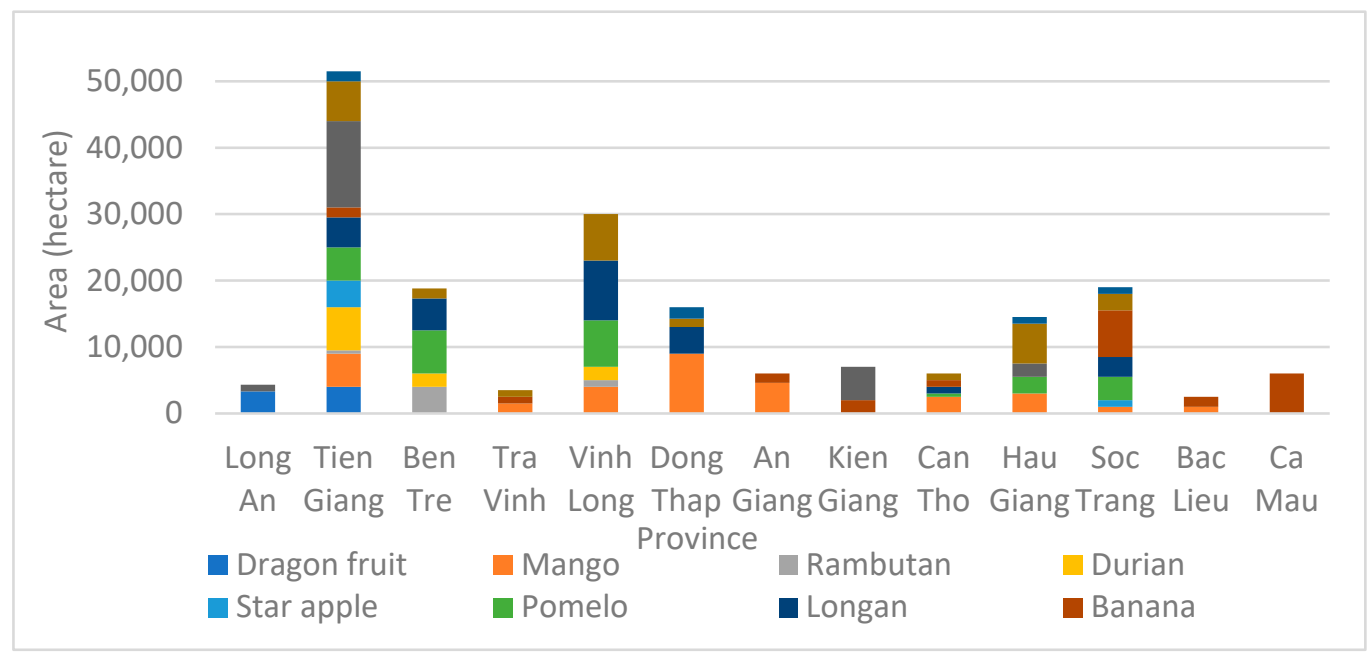

Figure 3. Cultivation planned distribution by province.

In the supply chain's second and third echelons, potential locations for local hubs and crossdocking centers are identified in the centers of the provinces where both roadway and inland waterway transportation (IWT) is possible. In the fourth echelon, stores are also selected in the central cities of the Mekong Delta provinces together with Ho Chi Minh City, the largest economic and commercial center in the south of Vietnam. The distance between locations, unit transportation cost, vehicles specifications, and transportation environmental emission factor was determined according to the study on multimodal transportation in this area [39]. The transportation vehicles which were selected in the study have medium and small payloads as presented in Table 6 because infrastructure such as roads, bridges, and rivers are not suitable for heavy vehicles. Consumption demand was estimated based on the result of The Vietnam Household Living Standards Survey 2018 published by the Vietnam National General Statistics Office [40].

Table 6. Vehicle specifications.

\begin{tabular}{ccc}
\hline Specifications & Roadway & Inland Waterway \\
\hline Vehicle payload (ton) & 20 & 50 \\
Average velocity (Km/hour) & 50 & 10 \\
Emission (Kg CO2/ton-km) & 0.05654 & 0.15310 \\
\hline
\end{tabular}

For these facilities, construction scale consists of 3 levels presented in Table 7 through the analysis of annual consumption and transportation demand. The workforce at these facilities has an annual working hour of 2224 with an estimated cost of 5590 USD per person. 
Table 7. Facility capacity and investment cost.

\begin{tabular}{ccccc}
\hline \multirow{2}{*}{ Scale } & \multicolumn{2}{c}{ Local Collection Hub } & \multicolumn{2}{c}{ Crossdocking Center } \\
\cline { 2 - 5 } & $\begin{array}{c}\text { Designed Capacity } \\
\text { (Ton/Year) }\end{array}$ & $\begin{array}{c}\text { Investment } \\
\text { Cost (USD) }\end{array}$ & $\begin{array}{c}\text { Designed Capacity } \\
\text { (Ton/Year) }\end{array}$ & $\begin{array}{c}\text { Investment } \\
\text { Cost (USD) }\end{array}$ \\
\hline 1 & 120,000 & 96,750 & $1,200,000$ & $1,161,000$ \\
2 & 240,000 & 245,100 & $1,920,000$ & $1,935,000$ \\
3 & 360,000 & 335,400 & $2,400,000$ & $2,128,500$ \\
\hline
\end{tabular}

\subsection{Optimization Solutions}

This study finds the optimal solution for the objective functions alternately using IBM CPLEX version 12.6.2. The results of these optimization attempts are summarized and presented in Table 8.

Table 8. Optimization runs.

\begin{tabular}{|c|c|c|c|c|}
\hline Objective Value & Minimize $f^{1}$ & Minimize $f^{2}$ & Minimize $f^{3}$ & Minimize $f^{4}$ \\
\hline $\begin{array}{l}\text { Total cost } \\
\text { (USD) }\end{array}$ & $66,903,479$ & $110,975,279$ & $290,631,549$ & $111,662,385$ \\
\hline $\begin{array}{l}\text { Total delivery time } \\
\text { (hour) }\end{array}$ & $1,098,291$ & 491,200 & $3,213,428$ & 491,492 \\
\hline $\begin{array}{l}\text { On-time delivery } \\
\text { factor (hour) }\end{array}$ & 86,386 & 86,147 & 52,877 & 86,160 \\
\hline $\begin{array}{c}\text { Transportation } \\
\text { emissions } \\
\text { (Kg CO } 2)\end{array}$ & $83,750,964$ & $28,196,007$ & $223,276,145$ & $28,121,281$ \\
\hline
\end{tabular}

Accordingly, the optimal value of the target functions that are solved separately $f^{*}=\left(f^{1 *}, f^{2 *}, f^{3 *}, f^{4 *}\right)=(66,903,479,491,200,52,877,28,121,281)$. The next step, this study surveyed twenty experts, stakeholders in this supply chain, including agricultural collectors, traders, carriers, retailers, and government regulators on the importance of the above target functions. Based on the survey's results, pairwise comparison matrices were constructed and they are used to calculate the weights of the objective functions according to Equation (6), which are shown in Table 9.

Table 9. Objective function weights.

\begin{tabular}{|c|c|c|c|c|c|}
\hline \multirow{2}{*}{ Expert } & \multicolumn{4}{|c|}{ Weight } & \multirow{2}{*}{ Consistency Ratio (\%) } \\
\hline & $f^{1}$ & $f^{2}$ & $f^{3}$ & $f^{4}$ & \\
\hline 1 & 0.3645 & 0.1242 & 0.2336 & 0.2777 & 1.70 \\
\hline 2 & 0.5438 & 0.2243 & 0.1030 & 0.1289 & 5.09 \\
\hline 3 & 0.2752 & 0.4671 & 0.1062 & 0.1515 & 3.60 \\
\hline 4 & 0.4053 & 0.1321 & 0.0867 & 0.3759 & 1.71 \\
\hline 5 & 0.3359 & 0.3754 & 0.1898 & 0.0989 & 4.42 \\
\hline 6 & 0.5443 & 0.1373 & 0.2424 & 0.0760 & 6.98 \\
\hline 7 & 0.3935 & 0.2337 & 0.0746 & 0.2982 & 5.71 \\
\hline 8 & 0.1766 & 0.2460 & 0.2956 & 0.2818 & 6.86 \\
\hline 9 & 0.4444 & 0.2416 & 0.2109 & 0.1031 & 6.40 \\
\hline 10 & 0.4718 & 0.2124 & 0.2174 & 0.0984 & 2.32 \\
\hline 11 & 0.0930 & 0.5249 & 0.2388 & 0.1433 & 3.25 \\
\hline 12 & 0.2044 & 0.5844 & 0.1124 & 0.0988 & 5.40 \\
\hline 13 & 0.1345 & 0.4811 & 0.2586 & 0.1258 & 4.39 \\
\hline 14 & 0.3302 & 0.0934 & 0.2062 & 0.3702 & 7.42 \\
\hline 15 & 0.3399 & 0.0935 & 0.2268 & 0.3398 & 4.60 \\
\hline 16 & 0.4409 & 0.1392 & 0.1638 & 0.2562 & 6.97 \\
\hline
\end{tabular}


Table 9. Cont.

\begin{tabular}{|c|c|c|c|c|c|}
\hline \multirow{2}{*}{ Expert } & \multicolumn{4}{|c|}{ Weight } & \multirow{2}{*}{ Consistency Ratio (\%) } \\
\hline & $f^{1}$ & $f^{2}$ & $f^{3}$ & $f^{4}$ & \\
\hline 17 & 0.1560 & 0.2854 & 0.4396 & 0.1190 & 5.37 \\
\hline 18 & 0.3704 & 0.1464 & 0.2780 & 0.2052 & 7.66 \\
\hline 19 & 0.4527 & 0.0990 & 0.1708 & 0.2775 & 8.26 \\
\hline 20 & 0.3319 & 0.1257 & 0.2348 & 0.3076 & 3.01 \\
\hline
\end{tabular}

The table above shows that the consistency ratio in the pairwise comparison matrices are less than $10 \%$. The weights of the objective functions calculated according to Equation (7) $W^{p}=\left(W^{1}, W^{2}, W^{3}, W^{4}\right)=(0.3405,0.2483,0.2045,0.2067)$. Thus, the weighted balancing objective function of this case study is defined as Equation (28).

$$
\begin{aligned}
\text { Minimize } f= & 0.3405 \times\left(\frac{f^{1}-66,903,479}{66,903,479}\right)+0.2483 \times\left(\frac{f^{2}-491,200}{491,200}\right) \\
& +0.2045 \times\left(\frac{f^{3}-52,877}{52,877}\right)+0.2067 \times\left(\frac{f^{4}-28,121,281}{28,121,281}\right)
\end{aligned}
$$

The optimal solution is obtained through solving the model with the above weighted balancing objective function, shown in Table 10. Accordingly, the relative gap between the values in this solution and the individual optimal values of $87.02 \%, 23.48 \%, 0.42 \%$, and $26.41 \%$, respectively.

Table 10. Multiple objective optimization result.

\begin{tabular}{lcc}
\hline \multicolumn{1}{c}{ Objective } & Minimize f \\
\hline Total cost (USD) & Investment cost & $125,120,510$ \\
& Labor cost & $8,675,250$ \\
& Transportation cost & $21,023,990$ \\
Total delivery time (hour) & $95,421,270$ \\
On-time delivery factor (hour) & 606,547 \\
Transportation emissions (Kg CO2) & 53,101 \\
\hline
\end{tabular}

For facility related decisions, the solution proposes setting up local collection hubs in all Mekong Delta provinces with a workforce level of 1885 employees. The crossdocking centers employ 1876 workers and are proposed to be established in LongAn, VinhLong, KienGiang, and SocTrang provinces. Proposed capacity and labor force allocation at these facilities are presented in Figures 4 and 5.

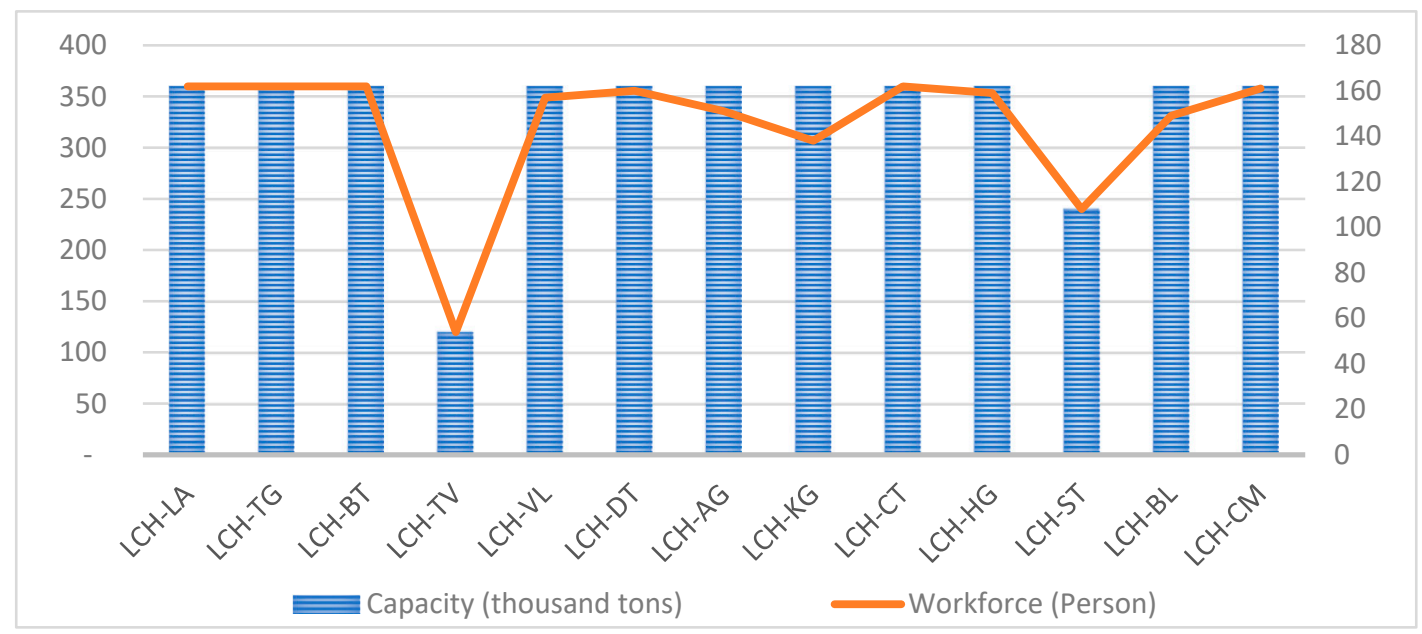

Figure 4. Local collection hub location, scale, and workforce level. 


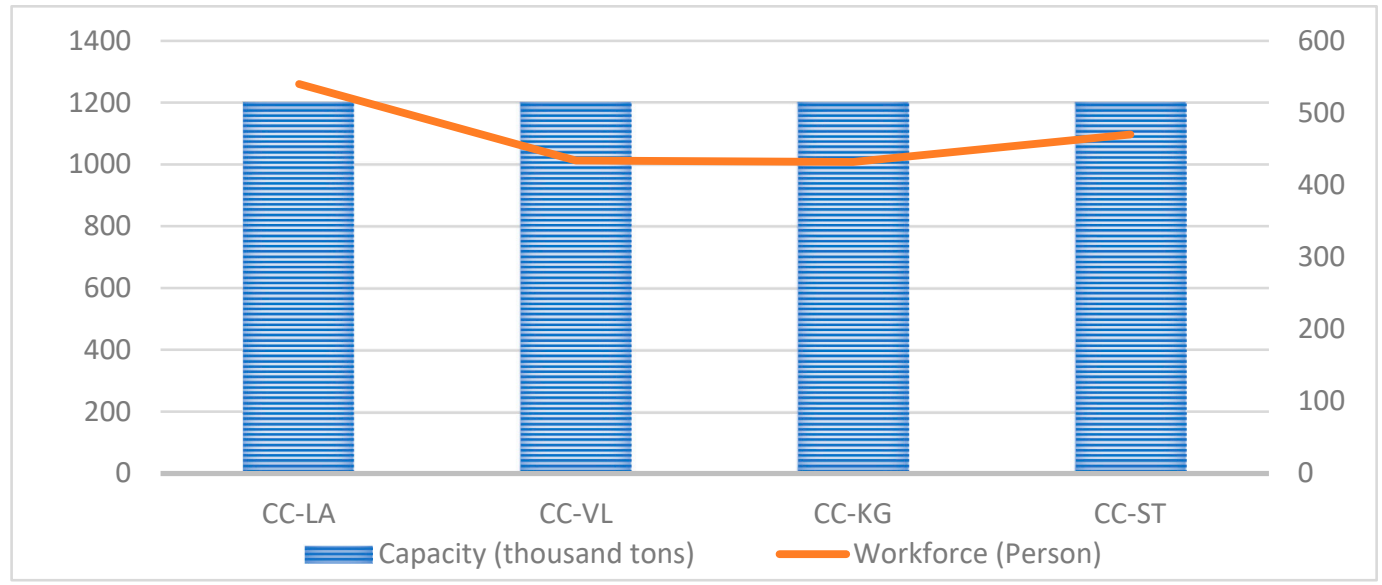

Figure 5. Crossdocking center location, scale, and workforce level.

Figure 4 shows the required presence of local collection hubs across provinces because of the great requirement for post-harvest fruit collection. In particular, locations with low yields such as LCH-TV and LCH-ST require lower design capacity and manpower than others. Through Figure 5, optimization model selected locations that are characterized by the advantages of geographical distance and the center of the cluster of fruit gardens with large yields. For example, CC-LA, although having low output, is the gateway connecting the Mekong Delta with Ho Chi Minh City, where the highest consumption demand in the South of Vietnam is. In terms of utilization, calculations show that the utilization of local collection hubs is in the range of $87.5 \%, 100 \%$, while for crossdocking centers is in the range of $80 \%, 100 \%$. This result of the model implies that the facilities selected through decision variables are highly efficient in terms of investment. The facility network of the Mekong delta region is presented in Figure 6.

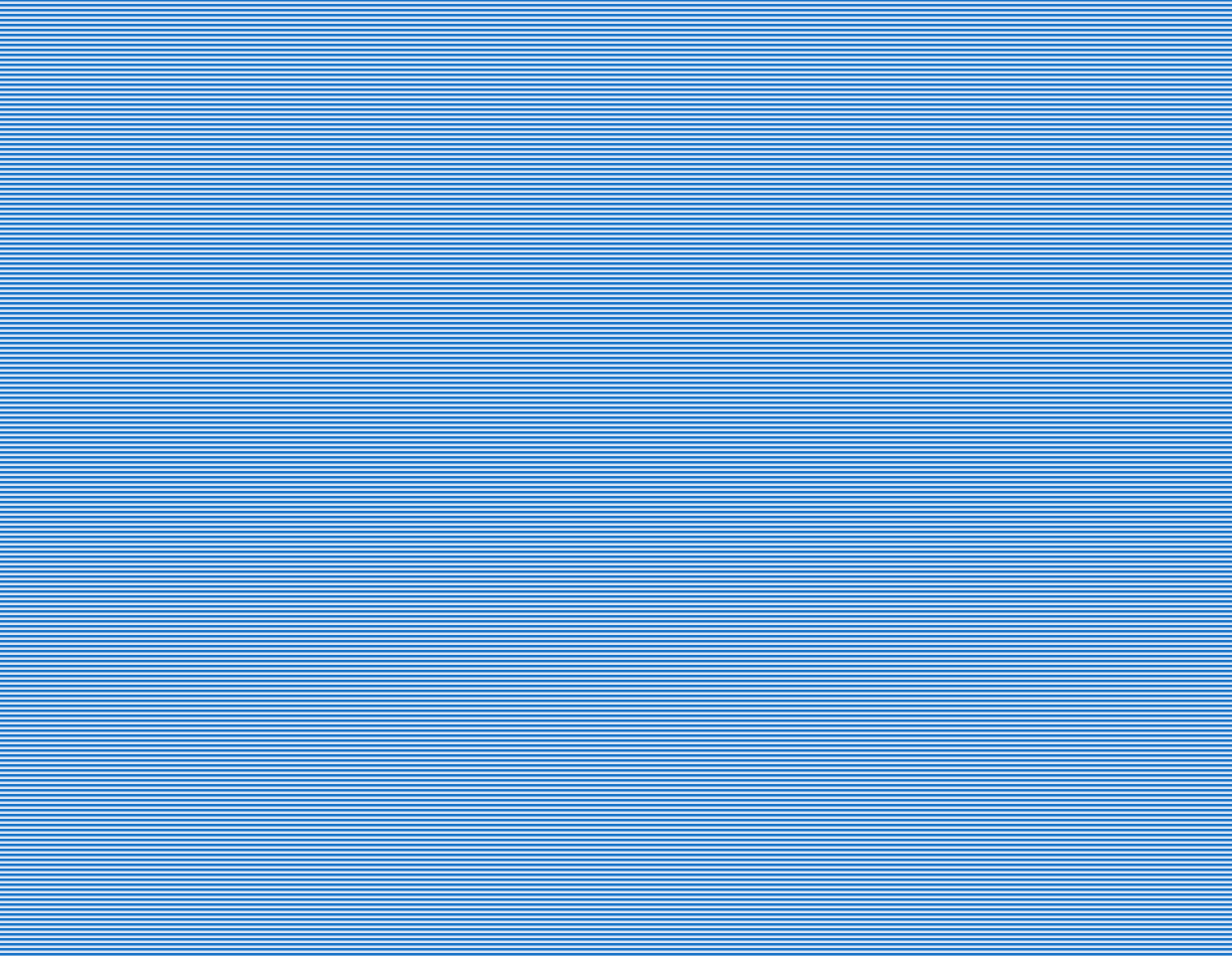

Figure 6. Facility network. 
Deciding which mode of transport is appropriate on each route depends on factors such as distance, cost, and emissions. Figure 7 illustrates the proportion between local roadway and IWT in the collection hub. In the LCH-LA hub, most of the fruit is received by the roadway, then transferred almost entirely to IWT. In contrast, the mode of transport is completely converted from IWT to the roadway at LCH-CM hub. The LCH-BT and $\mathrm{LCH}-\mathrm{TV}$ hub receive the goods by both modes of transport and then transfer them all over to the road. The hub LCH-CT and LCH-AG are more inclined to use a roadway, where the hub's primary role is not to convert transport modes but to perform quality control and packaging procedures. Other hubs do not have a significant change in the proportion of transportation modes. Through the results of the optimization of the model, the stakeholders of the supply chain can clearly orient the roles of different locations in the same echelon. As a result, it is possible to make decisions on investment in attached equipment and vehicles.

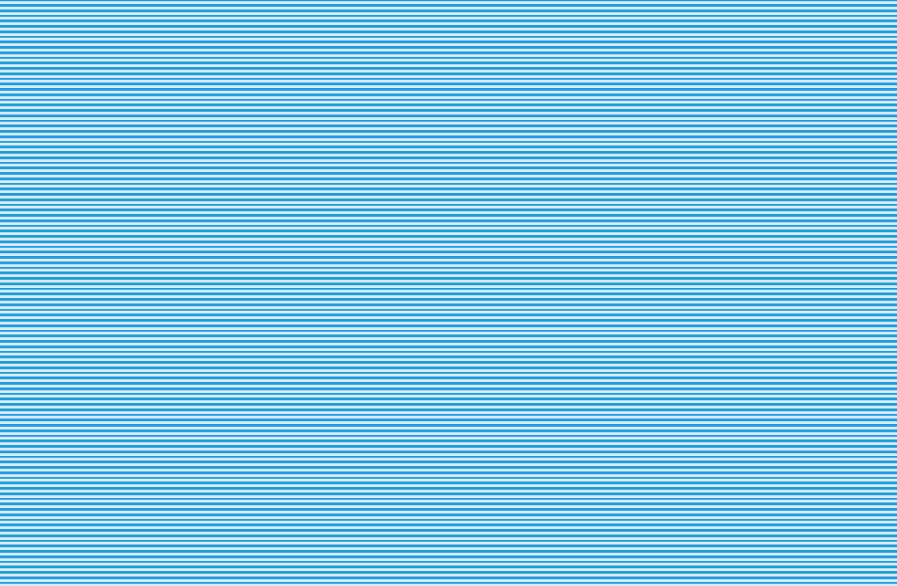

(a)

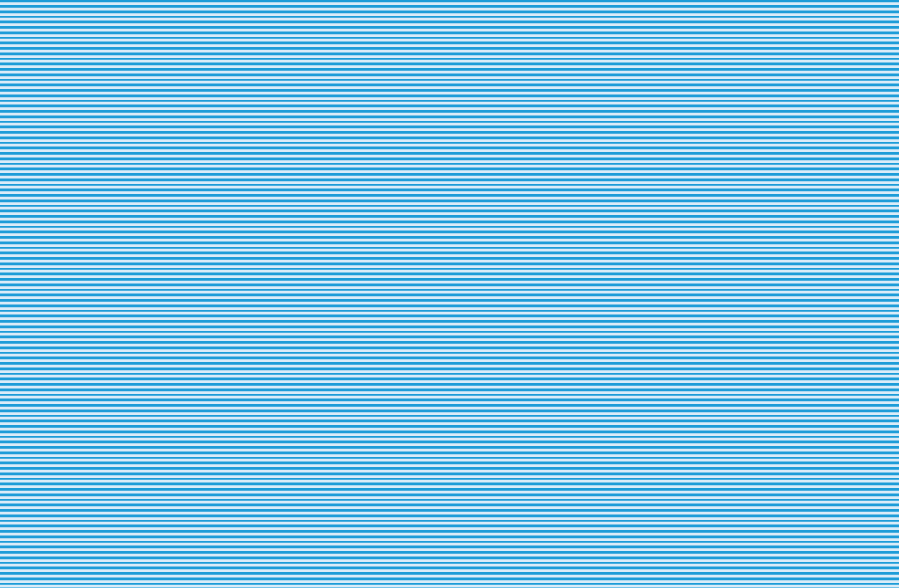

(b)

Figure 7. Proportion of transport modes at local collection hubs. (a) Receiving flow; (b) shipping flow.

Similarly, Figure 8 shows that crossdocking centers CC-LA and CC-VL mainly receive fruit by both modes of transport and implement crossdocking process according to the demand of each type of fruit at stores and mainly transporting by roadway.

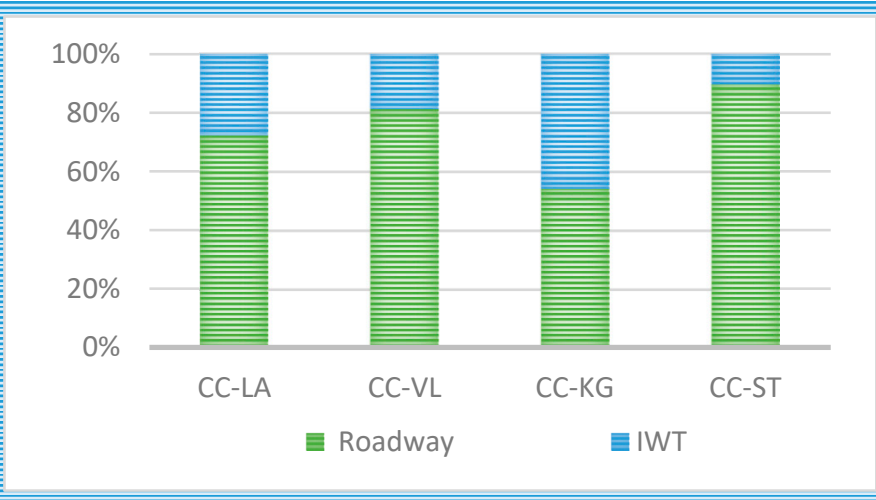

(a)

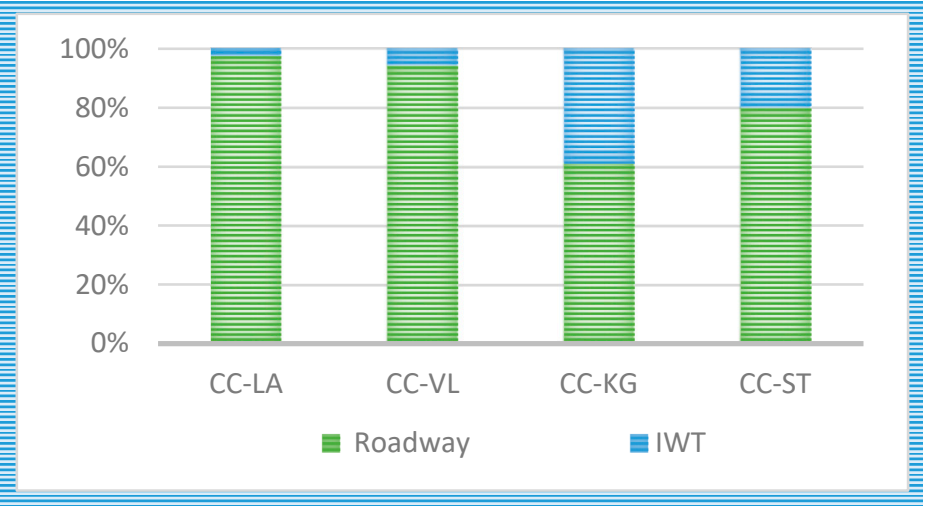

(b)

Figure 8. Proportion of transport modes at crossdocking center. (a) Receiving flow; (b) shipping flow.

According to this harvest and transport plan, Figure 9 shows star apple, pomelo, and oranges are less likely fruits that are not in time of high demand. Meanwhile, the lack of supply of high seasonal fruits such as rambutan, mango, and dragon fruit occurs at a 
higher frequency. As a result, supply chain stakeholders can make tactical decisions to influence market demand in addition to trying to influence the seasonal nature of these fruits through agricultural techniques.

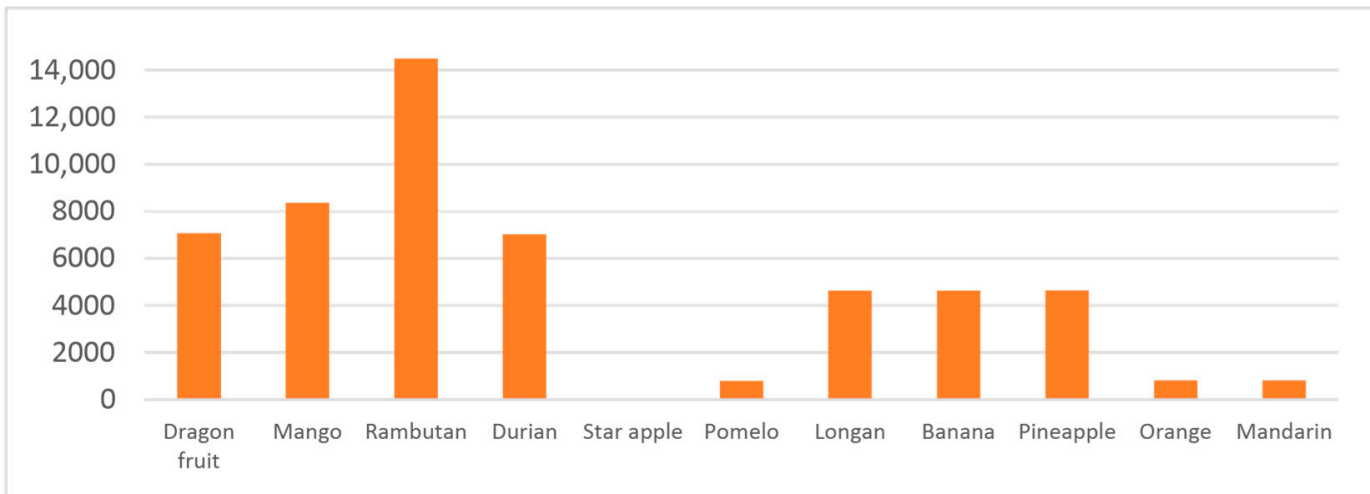

Figure 9. Early and delay time in transportation of fruits (hour).

In Figure 10, from the retail store's perspective, the supply chain operators can essentially judge the key product of each location. As at the RS-005 store, most fruits are readily available for sale at times when demand is high, resulting in more profit and guaranteed revenue. At other stores, such as RS-003 and RS-014, supply and demand of durian and rambutan is often out of phase. This foreseen shortage helps the retailer better manage their sales and inventory of perishable items such as fruit. Thus, an optimal solution supports the decisions both tactics and strategy in the design and operation of the supply chain of fresh fruit.

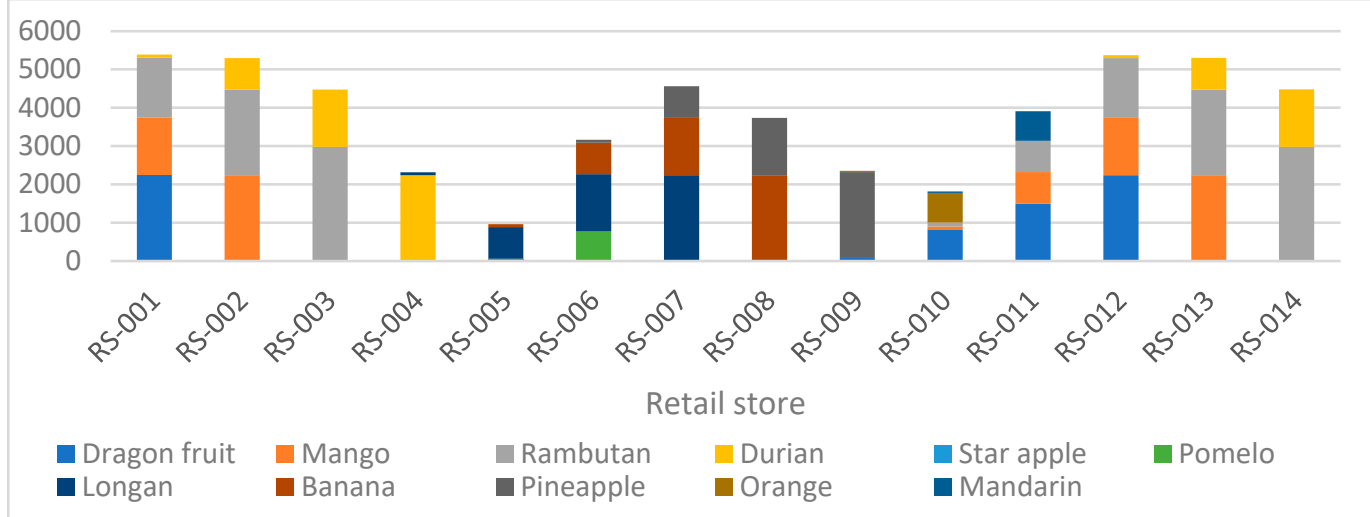

Figure 10. Early and delay time at retail stores (hour).

\subsection{Experiments}

According to Equation (28), the value of the decision variables in the solution of the model is influenced by the weights of the objective functions, thereby leading to a change in the supply chain configuration. In order to analyze those changes, the authors build scenarios as shown in Table 11 on the basis of adjusting the weights of the objective functions in which the solution above is noted as the Scenario-0.

The scenarios proposed by the authors is in the direction of shifting the importance of the cost target function to sustainability objective functions. According to the stakeholder survey, the weighting of the cost objective function is $30.3 \%$. In Scenario-1, the weighting of costs is reduced to an equilibrium level with the rest, while Scenario- 2 focuses more on the delivery time in the supply chain. The impact of market demand and transport emissions is more important in Scenario-3 and Scenario-4, respectively. 
Table 11. Scenarios description.

\begin{tabular}{ccccc}
\hline \multirow{2}{*}{ Scenario } & \multicolumn{3}{c}{ Weight } \\
\cline { 2 - 5 } & $\boldsymbol{f}^{\mathbf{1}}$ & $\boldsymbol{f}^{\mathbf{2}}$ & $\boldsymbol{f}^{\mathbf{3}}$ & $f^{\mathbf{4}}$ \\
\hline Scenario-0 & 0.303 & 0.215 & 0.191 & 0.291 \\
Scenario-1 & 0.250 & 0.250 & 0.250 & 0.250 \\
Scenario-2 & 0.200 & 0.500 & 0.150 & 0.150 \\
Scenario-3 & 0.150 & 0.150 & 0.500 & 0.200 \\
Scenario-4 & 0.100 & 0.100 & 0.300 & 0.500 \\
\hline
\end{tabular}

Table 12 shows the variation of the value of the target functions between scenarios compared to Scenario-0. Because of the adjustment towards reducing the weight of the cost-objective function, scenarios all have a higher cost of Scenario-0 from 3.67 to $5.62 \%$. With higher weights, as in Scenario-4, emissions are reduced by $10.54 \%$. Thus, that implies that the efficiency of reducing emissions in the supply chain increases as this factor is appreciated by stakeholder. Besides, the increasing weight also helps improve delivery time; however, this improvement is also influenced by cost and emission weights, mainly because of decisions related to the mode of transport. For total early or late delivery time, the weight changes in the weighted balancing objective function are not as significant as when optimizing this factor individually.

Table 12. Scenario's objective functions performance changes.

\begin{tabular}{ccccc}
\hline Objective & Scenario-1 & Scenario-2 & Scenario-3 & Scenario-4 \\
\hline $\begin{array}{c}\text { Total cost } \\
\text { (USD) }\end{array}$ & $-3.6677 \%$ & $-5.1133 \%$ & $-4.0346 \%$ & $-5.6211 \%$ \\
$\begin{array}{c}\text { Total delivery } \\
\text { time } \\
\text { (hour) }\end{array}$ & $1.3177 \%$ & $2.3243 \%$ & $7.6035 \%$ & $7.2972 \%$ \\
$\begin{array}{c}\text { On-time delivery } \\
\text { factor } \\
\text { (hour) }\end{array}$ & $-0.4670 \%$ & $-0.0810 \%$ & $0.0000 \%$ & $0.0075 \%$ \\
$\begin{array}{c}\text { Transportation } \\
\text { emissions } \\
\text { (Kg CO2) }\end{array}$ & $3.5895 \%$ & $5.5664 \%$ & $10.1131 \%$ & $10.5422 \%$ \\
\hline
\end{tabular}

As shown in Figure 11, the designed capacity of local collection hubs at the LCH-LA, LCH-TG, LCH-BT, LCH-VL, LCH-DT, LCH-AG, and LCH-HG, there is no significant difference among the scenarios. This implies critical role of this local collection hub in the supply chain. On the other hand, LCH-KG and LCH-CM are more suited to the supply chain with a focus on cost effectiveness. On the contrary, when the sustainability factors are more concerned, LCH-TV and LCH-ST are suggested to invest with a larger capacity. Workforce level fluctuations mainly occur at LCH-AG, LCH-KG, LCH-ST, LCH-BL, and $\mathrm{LCH}-\mathrm{CM}$ locations that are in the southwestern region of the Mekong Delta and are far from Ho Chi Minh city.

According to the optimization results of the scenarios on the location of crossdocking centers as shown in Figure 12, the solutions of all scenarios choose CC-LA in which Scenario-4 is recommended for the highest capacity and workforce level. A low-capacity crossdocking center is recommended at the CC-KG site for a cost-focused supply chain. This crossdocking center is recommended to develop in other positions such as CC-CT and CC-BL when the weights of the objective functions change in the direction of minimizing emissions. Scenario-0 and Scenario-3 solution decided to invest in four low-capacity crossdocking centers while Scenario-1, Scenario-2, and Scenario-4 decided to develop less crossdocking centers but with higher capacity. 


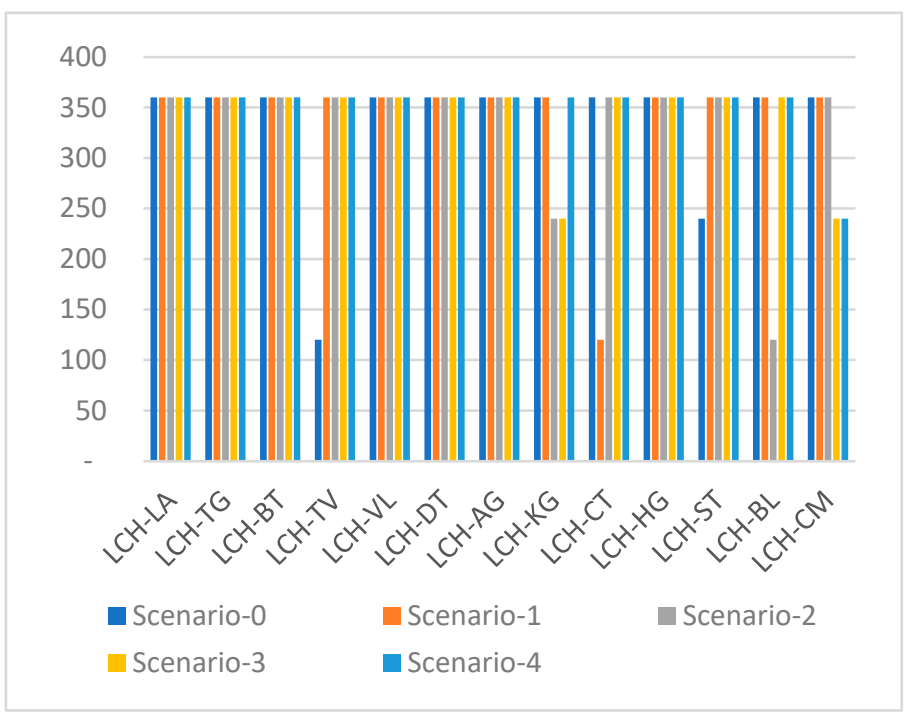

(a)

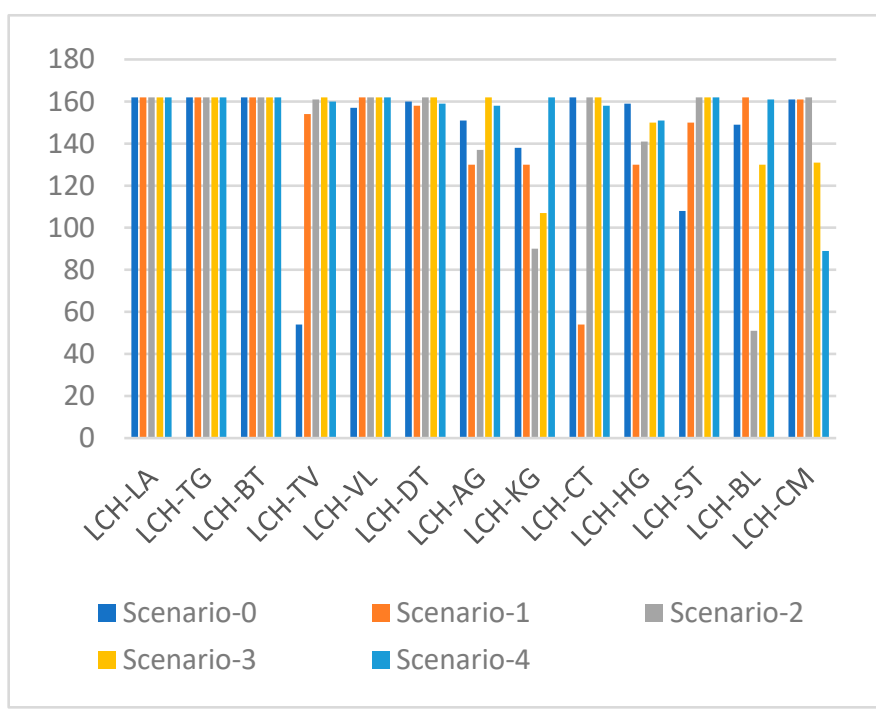

(b)

Figure 11. Scenario's local collection hub locations. (a) Capacity; (b) workforce level.

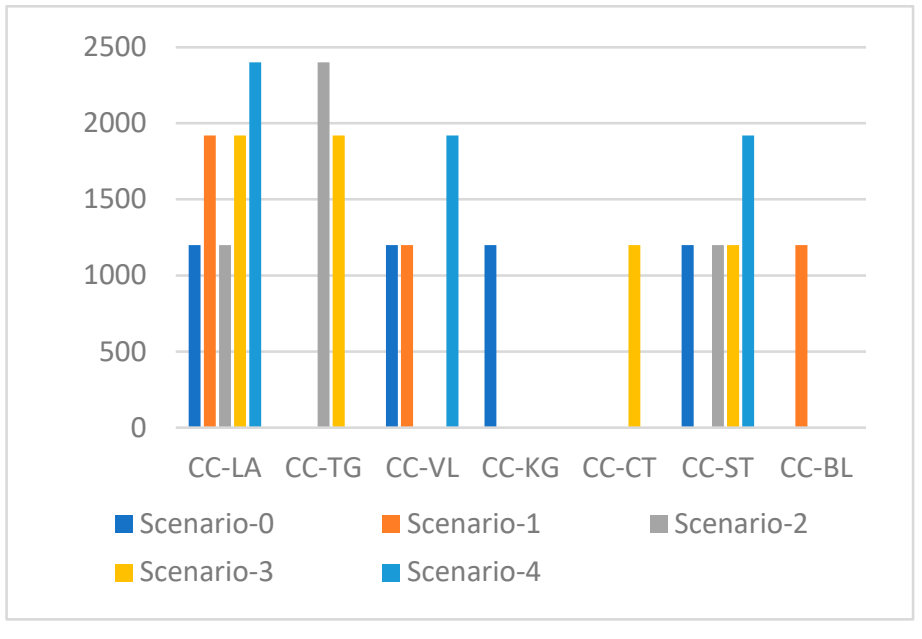

(a)

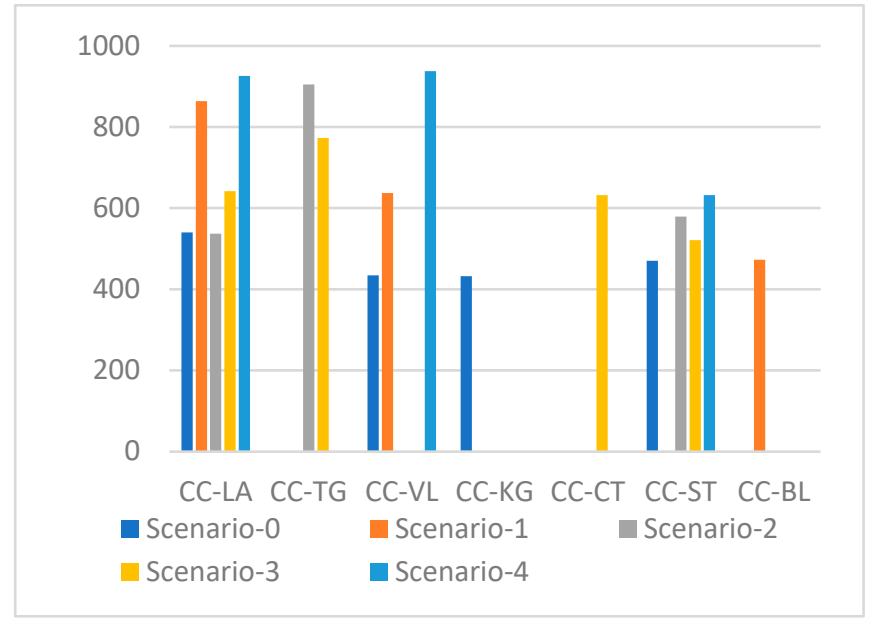

(b)

Figure 12. Scenario's crossdocking center locations (a) Capacity; (b) workforce level.

Figures 13-15 show that the more towards the end of the supply chain, the more road transport mode is used. The transportation between the first and second echelon of the supply chain has a higher proportion of the IWT. In addition, through the interpretation of the scenarios, it can be seen that as the consideration of costs decreases, the proportion of IWT use decreases.

In summary, the weighting of the objective functions has a significant effect on the strategic and tactical decisions of the supply chain that are suggested by the model's solution. In order to develop sustainably, economic efficiency may be sacrificed and vice versa. The above trade-offs are determined by stakeholder's views throughout the supply chain. However, because conflicts of interest may exist between stakeholders, the determination of weights between the target functions also requires the participation of experts and government managers. In addition, there is a need to increase the number of experts who are surveyed for the importance of the target functions in order to achieve a harmonious effect in the design and operation of the supply chain. 


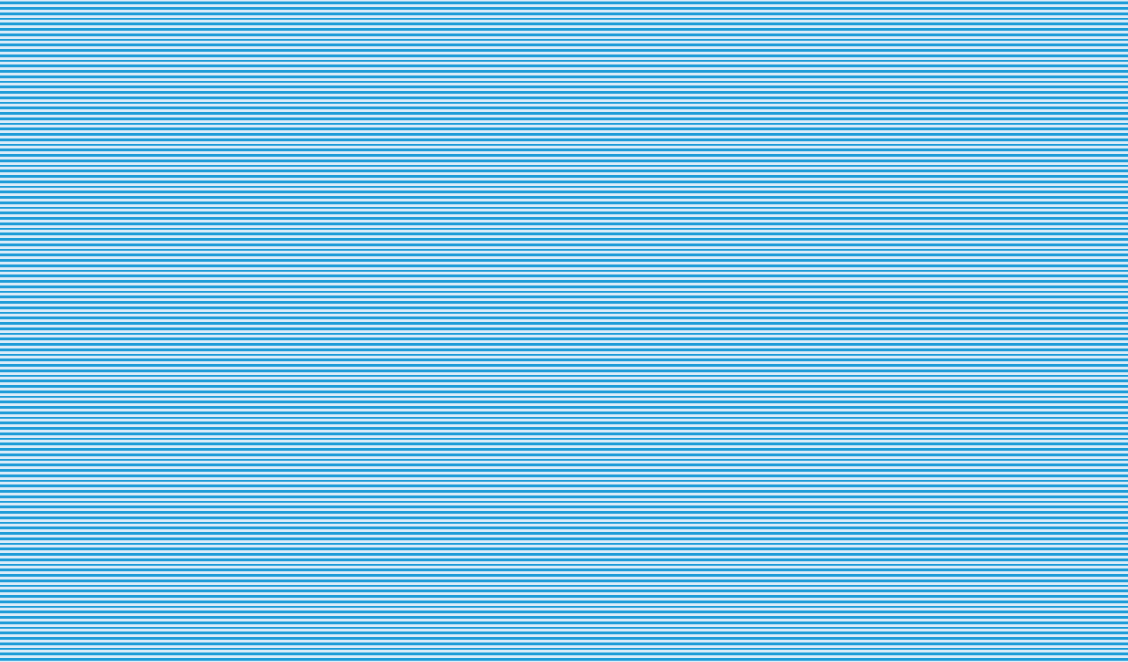

Figure 13. Proportion of transport modes from fruit garden to local collection hub.

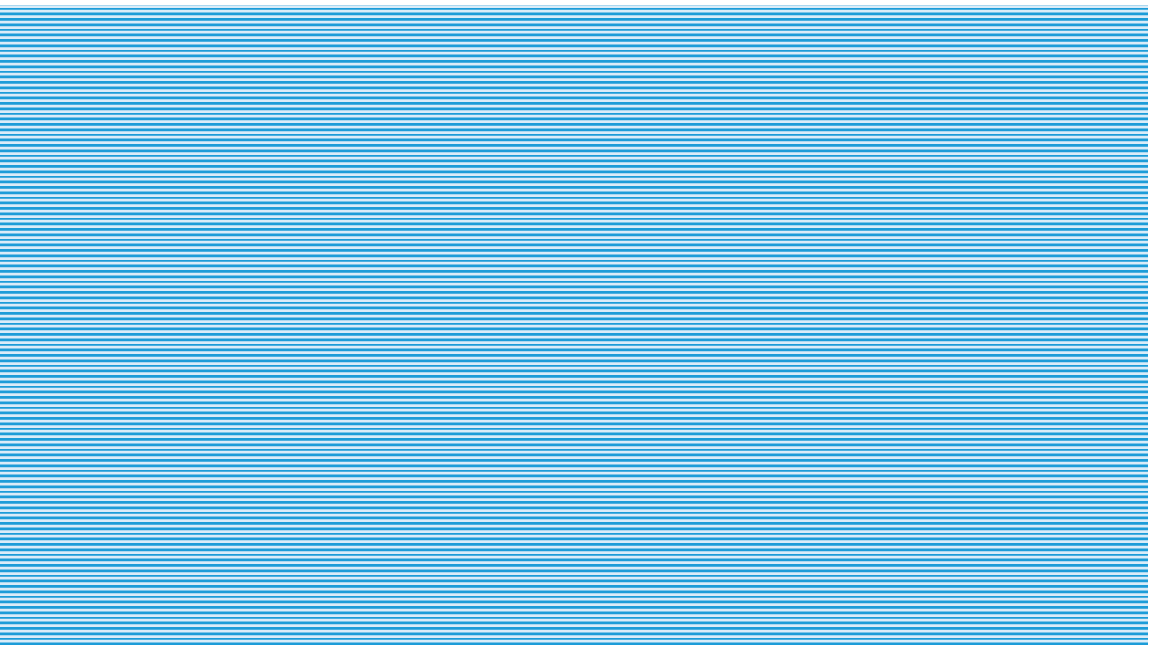

Figure 14. Proportion of transport modes from local collection hub to crossdocking center.

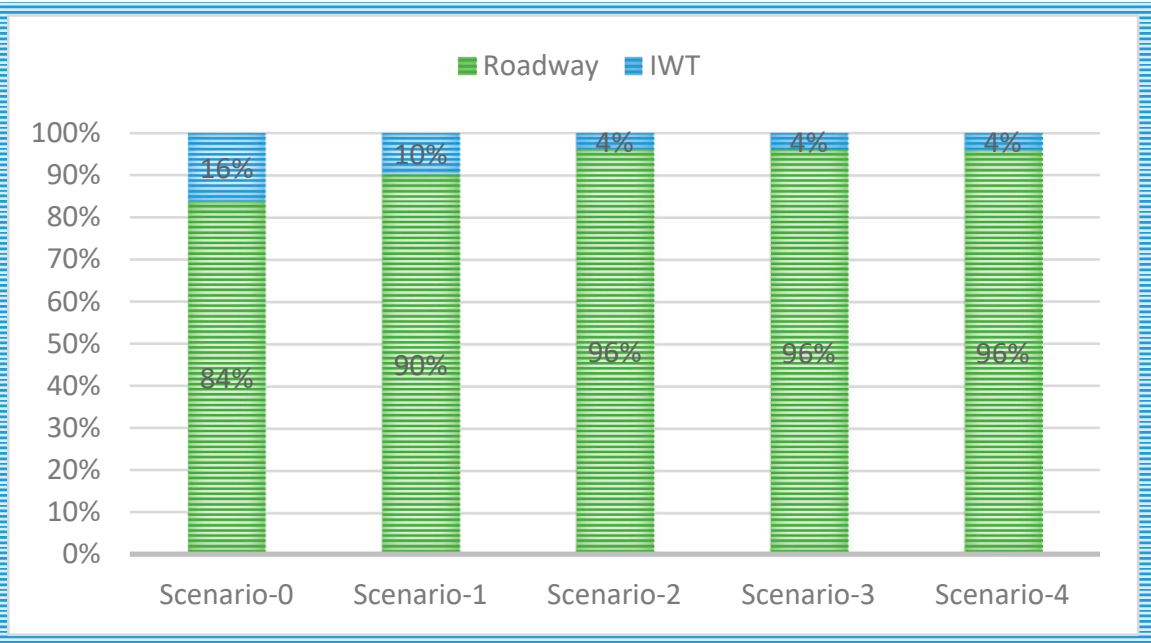

Figure 15. Proportion of transport modes from crossdocking center to retailer store.

\section{Conclusions}

This research develops a multi-objective, multi-product MIP model for the fourechelon intermodal SPSCNDP. As a tool to aid strategic and tactical decision-making, the 
model encompasses decision variables about the location and size of investment in facilities, workforce level, transport mode, and product flow. The objective functions considered in the model include costs, delivery time, emissions, and the match between supply and demand in terms of time. The study also introduced a new approach to combine and standardize those objective functions into a weighted single objective. The weights were estimated by the stakeholder's pairwise comparison survey. The model applied to the case of the fresh fruit industry of Mekong Delta, Vietnam. The case study covers eleven major types of fruit from thirteen fresh fruit supply zones. Thirteen potential locations for local collection hubs were responsible for the processes of collecting and packing fresh fruit, and an equivalent number of potential locations for the center crossdocking in the role of distributing goods based on demand of fourteen retail stores. Supply chain configuration is recommended for managers through the solution of the model with a weighted objective function that is governed by the view of twenty stakeholders. Moreover, scenarios are developed based on changing weights to predict the variation of supply chain configuration.

In summary, the contributions of this study include (1) theoretical reinforcement of the optimization studies for intermodal SPSCNDPs with a multi-objective, multi-product MIP model. Current applications of the MIP model for SPSCNDPs are mainly focused on the economic and environmental objective functions [41,42], while others consider the total time in the supply chain, which is the critical factor in perishable products [43]. The most differentiation of the MIP model proposed by this study is the objective function related to early and late delivery time with time windows. Accordingly, at the two poles of the supply chain, the demand for consumption and harvesting is seasonal. Their seasonal variation affects the value of products on the market according to the principle of supply and demand. This time difference can be influenced by agricultural techniques at the supplier or retail sales strategies. However, this MIP model is a step towards controlling this phase difference through the planned harvest and transport through the facilities. For the variables, in addition to typical decisions of the supply chain network design problem, the model also supports decisions about the workforce level, the facility capacity, and the transportation timing. Moreover, the study also applies a weighting technique between the objective functions and suggests an approach to combine and standardize the objective functions. (2) Consulting in management practice, the research solution supports supply chain managers in Vietnam including companies, investors, nonprofits, and government as a strategic reference in fresh fruit supply chain design and operation. The solution covers the Mekong Delta's characteristics such as main fruits, cultivated area, yield, seasonality, and transport infrastructure. Lack of planning and the absence of a well-integrated supply chain both vertically and horizontally are an ongoing situation for the fruit and agricultural industry in Vietnam [44]. The fruits of the Mekong Delta are being distributed by traditional channels or retailers. Traditional distribution channels are proving ineffective compared to the development trend of this industry in the world. Meanwhile, the fresh fruit supply chains of retailers are mostly focused on purchasing and distributing according to the changing market demand. As a result, players at the beginning of the supply chain such as farmers and small traders are exposed to risks due to a lack of market information, which leads to difficulties in planning the cultivation and harvesting. Therefore, this study provides a useful reference for government regulators, retailers, farmers, and traders to develop a sustainable shared supply chain for fruit in the Mekong Delta. (3) Moreover, the trade-offs between economic efficiency, delivery time, environmental impact, and customer satisfaction impact on the fresh fruit supply chain were also analyzed by the authors. Thereby, the study provides a basis for managers to make long-term predictions about the variation in design when the objective's importance changes according to regional, national, and global development requirements.

Future studies can overcome the limitations of this research through the following directions. First, researchers may consider uncertain parameters in the model such as market demand or delivery times. Second, the modes of transport used in the supply chain 
may be increased according to the regional infrastructure characteristics that are applied in the study. Third, social policies in labor management such as overtime, hiring, and layoffs can increase the practicality of the model. Finally, future studies may apply to other product groups that are perishable.

Author Contributions: Conceptualization, Y.-C.C., N.-L.N. and H.-T.P.; methodology, C.-N.W., N.L.N. and H.-T.P.; formal analysis, N.-L.N. and H.-T.P.; investigation, N.-L.N. and H.-T.P.; data curation, N.-L.N. and H.-T.P.; writing-original draft preparation, N.-L.N. and H.-T.P.; writing-review and editing, C.-N.W., Y.-C.C. and N.-L.N.; project administration, C.-N.W. and Y.-C.C.; funding acquisition, C.-N.W. All authors have read and agreed to the published version of the manuscript.

Funding: The research was partly supported by the National Kaohsiung University of Science and Technology, and MOST 109-2622-E-992-026 from the Ministry of Sciences and Technology in Taiwan.

Acknowledgments: The authors appreciate the support from the National Kaohsiung University of Science and Technology and the Ministry of Sciences and Technology in Taiwan.

Conflicts of Interest: The authors declare no conflict of interest.

\section{References}

1. Routray, W.; Orsat, V. Agricultural and Food Industry By-Products: Source of Bioactive Components for Functional Beverages. Nutr. Beverages 2019, 12, 543-589.

2. Harris, J.; Nguyen, P.H.; Tran, L.M.; Huynh, P.N. Nutrition transition in Vietnam: Changing food supply, food prices, household expenditure, diet and nutrition outcomes. Food Secur. 2020, 12, 1141-1155. [CrossRef]

3. González-Aguilar, G.; Robles-Sánchez, R.; Martínez-Téllez, M.; Olivas, G.; Alvarez-Parrilla, E.; de la Rosa, L. Bioactive compounds in fruits: Health benefits and effect of storage conditions. Stewart Postharvest Rev. 2008, 4, 1-10.

4. Wang, C.-N.; Nguyen, M.N.; Le, A.L.; Tibo, H. A DEA Resampling Past-Present-Future Comparative Analysis of the Food and Beverage Industry: The Case Study on Thailand vs. Vietnam Math. 2020, 8, 1140. [CrossRef]

5. Amorim, P.; Meyr, H.; Almeder, C.; Almada-Lobo, B. Managing perishability in production-distribution planning: A discussion and review. Flex. Serv. Manuf. J. 2011, 25, 389-413. [CrossRef]

6. Osvald, A.; Stirn, L.Z. A vehicle routing algorithm for the distribution of fresh vegetables and similar perishable food. J. Food Eng. 2008, 85, 285-295. [CrossRef]

7. Govindan, K.; Jafarian, A.; Khodaverdi, R.; Devika, K. Two-echelon multiple-vehicle location-routing problem with time windows for optimization of sustainable supply chain network of perishable food. Int. J. Prod. Econ. 2014, 152, 9-28. [CrossRef]

8. Kannan, D.; Mina, H.; Nosrati-Abarghooee, S.; Khosrojerdi, G. Sustainable circular supplier selection: A novel hybrid approach. Sci. Total Environ. 2020, 722, 137936. [CrossRef] [PubMed]

9. Koberg, E.; Longoni, A. A systematic review of sustainable supply chain management in global supply chains. J. Clean. Prod. 2019, 207, 1084-1098. [CrossRef]

10. Wang, C.-N.; Ho, H.-X.; Luo, S.-H.; Lin, T.-F. An Integrated Approach to Evaluating and Selecting Green Logistics Providers for Sustainable Development. Sustainability 2017, 9, 218. [CrossRef]

11. Wang, C.-N.; Nguyen, H.-K. Enhancing Urban Development Quality Based on the Results of Appraising Efficient Performance of Investors-A Case Study in Vietnam. Sustainability 2017, 9, 1397. [CrossRef]

12. Sirilertsuwan, P.; Thomassey, S.; Zeng, X. A Strategic Location Decision-Making Approach for Multi-Tier Supply Chain Sustainability. Sustainability 2020, 12, 8340. [CrossRef]

13. Hsu, H.-P.; Wang, C.-N. Resources Planning for Container Terminal in a Maritime Supply Chain Using Multiple Particle Swarms Optimization (MPSO). Mathematics 2020, 8, 764. [CrossRef]

14. Eskandarpour, M.; Dejax, P.; Miemczyk, J.; Péton, O. Sustainable supply chain network design: An optimization-oriented review. Omega-Int. J. Manag. Sci. 2015, 54, 11-32. [CrossRef]

15. Alizadeh Afrouzy, Z.; Nasseri, S.H.; Mahdavi, I.; Paydar, M.M. A fuzzy stochastic multi-objective optimization model to configure a supply chain considering new product development. Appl. Math. Model. 2016, 40, 7545-7570. [CrossRef]

16. Elhedhli, S.; Merrick, R. Green supply chain network design to reduce carbon emissions. Transport. Res. D-Tr. E. 2012, 17, 370-379. [CrossRef]

17. Zahir, S.; Sarker, R. Optimising multi-objective location decisions in a supply chain using an AHP-enhanced goal-programming model. Int. J. Logist. Syst. Manag. 2010, 6, 249-266. [CrossRef]

18. Bahrampour, P.; Safari, M.; Taraghdari, M.B. Modeling Multi-Product Multi-Stage Supply Chain Network Design. Proc. Econ. Financ. 2016, 36, 70-80. [CrossRef]

19. Farahani, R.Z.; Rezapour, S.; Drezner, T.; Fallah, S. Competitive supply chain network design: An overview of classifications, models, solution techniques and applications. Omega-Int. J. Manag. Sci. 2014, 45, 92-118. [CrossRef]

20. Sarker, B.; Jamal, A.M.M.; Wang, S. Supply chain model for perishable products under inflation and permissible delay in payment. Comput. Oper. Res. 2000, 27, 59-75. [CrossRef] 
21. Blackburn, J.; Scudder, G. Supply Chain Strategies for Perishable Products: The Case of Fresh Produce. Prod. Oper. Manag. 2009, 18, 129-137. [CrossRef]

22. Katsaliaki, K.; Mustafee, N.; Kumar, S. A game-based approach towards facilitating decision making for perishable products: An example of blood supply chain. Expert Syst. Appl. 2014, 41, 4043-4059. [CrossRef]

23. Liu, L.; Liu, X.; Liu, G. The risk management of perishable supply chain based on coloured Petri Net modeling. Inf. Process. Agric. 2018, 5, 47-59. [CrossRef]

24. Rong, A.; Akkerman, R.; Grunow, M. An optimization approach for managing fresh food quality throughout the supply chain. Int. J. Prod. Econ. 2011, 131, 421-429. [CrossRef]

25. Etemadnia, H.; Goetz, S.J.; Canning, P.; Tavallali, M.S. Optimal wholesale facilities location within the fruit and vegetables supply chain with bimodal transportation options: An LP-MIP heuristic approach. Eur. J. Oper. Res. 2015, 244, 648-661. [CrossRef]

26. de Keizer, M.; Akkerman, R.; Grunow, M.; Bloemhof, J.M.; Haijema, R.; van der Vorst, J.G.A.J. Logistics network design for perishable products with heterogeneous quality decay. Eur. J. Oper. Res. 2017, 262, 535-549. [CrossRef]

27. Dutta, P.; Shrivastava, H. The design and planning of an integrated supply chain for perishable products under uncertainties. $J$. Model. Manag. 2020, 15, 1301-1337. [CrossRef]

28. Bushuev, M.A.; Guiffrida, A.L. Optimal position of supply chain delivery window: Concepts and general conditions. Int. J. Prod. Econ. 2012, 137, 226-234. [CrossRef]

29. Catalá, L.P.; Moreno, M.S.; Blanco, A.M.; Bandoni, J.A. A bi-objective optimization model for tactical planning in the pome fruit industry supply chain. Comput. Electron. Agric. 2016, 130, 128-141. [CrossRef]

30. Razmi, J.; Kazerooni, M.P.; Sangari, M.S. Designing an integrated multi-echelon, multi-product and multi-period supply chain network with seasonal raw materials. Econ. Comput. Econ. Cybern. 2016, 50, 273-290.

31. Yu, M.-C.; Wang, C.-N.; Ho, N.-N.-Y. A Grey Forecasting Approach for the Sustainability Performance of Logistics Companies. Sustainability 2016, 8, 866. [CrossRef]

32. Musavi, M.; Bozorgi-Amiri, A. A multi-objective sustainable hub location-scheduling problem for perishable food supply chain. Comput. Ind. Eng. 2017, 113, 766-778. [CrossRef]

33. Biuki, M.; Kazemi, A.; Alinezhad, A. An integrated location-routing-inventory model for sustainable design of a perishable products supply chain network. J. Clean. Prod. 2020, 260, 120842. [CrossRef]

34. Wang, C.-N.; Dang, T.-T.; Le, T.Q.; Kewcharoenwong, P. Transportation Optimization Models for Intermodal Networks with Fuzzy Node Capacity, Detour Factor, and Vehicle Utilization Constraints. Mathematics 2020, 8, 2109. [CrossRef]

35. Bortolini, M.; Faccio, M.; Gamberi, M.; Pilati, F. Multi-objective design of multi-modal fresh food distribution networks. Int. J. Logist. Syst. Manag. 2016, 24, 155. [CrossRef]

36. Mohammed, A.; Wang, Q. The fuzzy multi-objective distribution planner for a green meat supply chain. Int. J. Prod. Econ. 2017, 184, 47-58. [CrossRef]

37. Accorsi, R.; Gallo, A.; Manzini, R. A climate driven decision-support model for the distribution of perishable products. J. Clean. Prod. 2017, 165, 917-929. [CrossRef]

38. Circular No.1648/QĐ-BNN-TT. July 2013. Available online: https:/ /luatvietnam.vn/nong-nghiep/quyet-dinh-1648-qd-bnn-ttbo-nong-nghiep-va-phat-trien-nong-thon-79898-d1.html (accessed on 30 June 2020).

39. Blancas, L.C.; El-Hifnawi, M.B. Facilitating Trade through Competitive, Low-Carbon Transport: The Case for Vietnam's Inland and Coastal Waterways; The World Bank: Washington, DC, USA, 2014.

40. The Vietnam Household Living Standards Survey 2018. May 2020. Available online: https://www.gso.gov.vn/en/data-andstatistics / 2020/05/result-of-the-vietnam-household-living-standards-survey-2018 (accessed on 27 July 2020).

41. Rohmer, S.U.K.; Gerdessen, J.C.; Claassen, G.D.H. Sustainable supply chain design in the food system with dietary considerations: A multi-objective analysis. Eur. J. Oper. Res. 2019, 273, 1149-1164. [CrossRef]

42. Jiang, Y.; Zhao, Y.; Dong, M.; Han, S. Sustainable Supply Chain Network Design with Carbon Footprint Consideration: A Case Study in China. Math. Prob. Eng. 2019, 2019, 1-19. [CrossRef]

43. Yakavenka, V.; Mallidis, I.; Vlachos, D.; Iakovou, E.; Eleni, Z. Development of a multi-objective model for the design of sustainable supply chains: The case of perishable food products. Ann. Oper. Res. 2019, 294, 593-621. [CrossRef]

44. Issues and Sustainable Development Orientation for Fruits in Mekong Delta. 2019. Available online: http:/ / www.cuctrongtrot. gov.vn/TinTuc/Index/4433. (accessed on 20 December 2020). 